\title{
CATHETER ABLATION OF LONE ATRIAL FIBRILLATION
}

Running title: Lone AF Ablation

\section{Authors:}

Nebojša M. Mujović ${ }^{1,2}$, Milan M. Marinković ${ }^{1}$, Tatjana S. Potpara ${ }^{1,2}$, László Gellér ${ }^{3}$

${ }^{1}$ Cardiology Clinic, Clinical Center of Serbia, Koste Todorovića 8, Belgrade 11000, Serbia

${ }^{2}$ Faculty of Medicine, University of Belgrade, Dr Subotića 8, Belgrade 11000, Serbia

${ }^{3}$ Cardiovascular Center, Semmelweis University, Városmajor utca 68, Budapest H-1122,

\section{$\underline{\text { Author for correspondence }}$}

Nebojša M. Mujović, MD

Department for Cardiac Electrophysiology, Cardiology Clinic,

Clinical Center of Serbia, Visegradska 26, 11000 Belgrade, Serbia

Cell phone: +381638422157

Phone (job): +381113616322

Fax number: +381113616318

E-mail: nmujovic@gmail.com 


\begin{abstract}
Atrial fibrillation is the most common sustained arrhythmia in clinical practice, associated with increased mortality, risk of stroke and heart failure, as well as the reduction of the quality of life. Atrial fibrillation may be encountered in young otherwise healthy individuals, due to the isolated electrophysiological disorder limited mostly to the pulmonary veins and posterior left atrial wall, or associated with the presence of advanced underlying heart disease and numerous cardiac and non-cardiac comorbidities with significant structural remodeling of the atrial myocardium. Due to limited efficacy and serious side effects of antiarrhythmic drugs, catheter ablation of atrial fibrillation, based on the pulmonary vein isolation for paroxysmal atrial fibrillation and adjunctive substrate modification for persistent atrial fibrillation, has emerged as an attractive and promissing alternative therapeutic option for selected patients with atrial fibrillation. In this review article, we discuss the electrophysiological left atrial abnormalities underlying lone atrial fibrillation and the role of pulmonary veins in pathophysiology of arrhythmia, and we summarize results of the studies on the long term outcome of catheter ablation of atrial fibrillation, as well as the studies on comparison of antiarrhythmic drugs with catheter ablation for treatment of atrial fibrillation. In addition, we present available data that provide better understanding of mechanisms, diagnosis, prevention and treatment of specific procedure-related complications and discuss current periprocedural anticoagulation strategies and their impact on the thromboembolic risk reduction.
\end{abstract}

Key words: atrial fibrillation; lone atrial fibrillation; pulmonary vein isolation; catheter ablation. 


\section{INTRODUCTION}

Atrial fibrillation (AF) is the most common sustained arrhythmia, with prevalence in general population of at least $1 \%$ [1]. The presence of AF increases mortality and risk of stroke and heart failure (HF), and the arrhythmia is often accompanied by limiting symptoms, such as palpitation and fatigue, thus reducing the quality of life (QoL) [1, 2]. From the clinical point of view, AF can be the manifestation of an isolated electrophysiological disorder, such as in patients with lone AF, or it can be associated with the presence of advanced structural heart disease and numerous cardiac and non-cardiac comorbidities. Triggers within the thoracic veins, usually the pulmonary veins (PVs), and fibrous-inflammatory substrate in left atrial (LA) myocardium are responsible for initiating and sustaining the arrhythmia. AF is a progressive disease, which often begins with paroxysms that gradually progress to persistent AF episodes and eventually to permanent AF. A lifelong antiarrhythmic drug (AAD) therapy has limited efficiency and many hazardous effects [1-3]. Over the last decade, catheter ablation of AF, based mainly on the electrical disconnection of PVs, has been considerably refined with the exponential increase in the number of the procedures each year, and today it represents one of the most common invasive electrophysiological interventions. The procedure provides non-pharmacological cure for selected patients with $\mathrm{AF}$ and is more efficient in rhythm control than medicament therapy [1, 3]. In this review article, we present an overview of (1) electrophysiological concept of catheter ablation of AF, (2) efficiency of AF ablation, (3) complications of AF ablation and (4) periprocedural anticoagulation.

\section{ELECTROPHYSIOLOGICAL AND STRUCTURAL ABNORMALITIES IN LONE AF}

AF occurs as the consequence of complex interaction of triggers, substrate and autonomic nervous system. Triggers are responsible for initiation of AF, while presence of substrate is responsible for its maintenance $[1,4]$. Changes in cardiac autonomic nervous system activity have significant influence on activity of the triggers and substrate for $\mathrm{AF}[1,5]$. AF is evolving disease and its pathophysiology and clinical presentation can vary. At one end of clinical spectrum there are younger patients with paroxysmal lone AF, which represents dominantly electrophysiological disorder, whereby the AF triggers are fundamental. At the opposite end are older patients with structural heart disease and persistent AF, whereby the development of atrial fibrous-inflammatory substrate could take the leading role in the AF mechanism [4, 6]. The most common AF triggers are the runs of atrial ectopic beats originating from the rapid firing foci. These foci are located mainly in the ending parts of PVs and rarely in other thoracic veins and atrial myocardium. PVs play the major role in the $\mathrm{AF}$ initiation and maintenance, especially among patients with lone AF. It has been shown that, in majority of patients $(94 \%)$, foci that initiated AF were located in $\geq 1 \mathrm{PV}[3,7]$. Non-PV triggers can be found in 6-10\% of the patients, most often in superior caval vein, vein of Marshall, coronary sinus, LA posterior wall, crista terminalis and LA appendage [3, 8]. During the embryonic heart development, PVs and LA posterior wall develop together from the sinus venosus containing numerous pacemaker cells with spontaneous automaticity, 
which originated from the remnants of primary specialized conduction tissue [9]. Myocardial fibers extend from the LA over the outer side of PVs, where they gradually rarefy and disappear after $1-3 \mathrm{~cm}$. These fibers have segmental distribution along circumference of PVs, with a multilayer spiral orientation and complex local nonuniform anisotropy and architecture; by their contractile function, these fibers regulate local vein blood flow [10]. Aforementioned histological features of PV-atrial junctions provide a precondition for increased automaticity, triggered activity, changes of the action potential duration, shortening of refractoriness, slow and decremental conduction and micro-reentry $[11,12]$. Besides that, dynamic neural activity of anatomically close ganglionated plexi, located at the PV-atrial junction level can significantly modify the local electrophysiological properties of PVs [13]. Appearance of AF episode is initially preceded by an increase in adrenergic tone with subsequent sudden change towards parasympathetic predomination [5]. Thus, a complex electrophysiological environment for induction and maintaining of lone AF episodes is formed.

The PVs and LA posterior wall are probably crucial for induction and maintaining of lone AF [4]. In one of the studies, the key role of PVs and LA posterior wall in pathophysiology of lone AF was clearly demonstrated. After surgical "en-block" isolation of PVs and LA posterior wall, electrophysiological study was carried out among the patients with lone AF (mean age 51, left atrial diameter $40 \mathrm{~mm}, 78 \%$ paroxysmal AF). In the isolated segment of LA, sustained AF was registered or short-lasting AF was induced, with signs of electrical dissociation from the remaining part of the LA, where sinus rhythm was maintained. On the other hand, AF could not be induced by aggressive stimulation of the remaining (non-isolated) part of the LA [14]. Another research showed that among patients with prolonged episodes of paroxysmal AF (43\% of the patients did not have structural heart disease) AF substrate was often limited to the PV region. By PV isolation during an ongoing episode of $\mathrm{AF}$, cycle length of $\mathrm{AF}$ was gradually prolonged in all patients, and $\mathrm{AF}$ was terminated in $75 \%$ of the patients. Furthermore, after PV isolation, AF remained non-inducible in $75 \%$ of the patients in whom it was induced prior to ablation [15]. Other authors also indicated that dominant rotors in lone AF were localized mostly in the region between LA posterior wall and PVs [9].

It was believed that progression of atrial disease with development of structural substrate in lone AF occurs solely as a consequence of tachycardia-induced (and potentially reversible) electrical LA remodelling due to frequent and prolonged episodes of the arrhythmia. However, in patients with paroxysmal lone AF (who did not suffer recent episode of AF) complex biatrial abnormalities were found in the form of structural changes with myocardial voltage reduction, slowing of conduction, prolongation of refractoriness and sinus node dysfunction, which could affect further progression of AF [16]. In addition, the histological examination revealed higher degree of patchy fibrosis of atrial myocardium among the patients with lone AF compared to healthy individuals [17]. Recent research with the use of cardiac MRI (Magnetic Resonance Imaging) showed that even in patients with lone AF extensive atrial structural remodelling can be found, primarily involving the LA posterior wall. Despite more frequent presence of paroxysmal type of arrhythmia among patients with lone $\mathrm{AF}$, there was no significant difference in the degree of structural abnormalities in comparison with "non-lone" AF patients [18]. 


\section{CATHETER ABLATION OF LONE AF}

Ablation strategy for lone AF. The patients with lone AF are probably among the best candidates for catheter ablation treatment and they have the highest chance for successful outcome of the procedure. Strategy of catheter ablation for lone AF does not differ from non-lone AF, mostly because it is the clinical type of AF (paroxysmal vs. persistent) which defines the choice of adequate ablation approach [3, 9, 19-28]. Favourable prognosis and survival, as well as low thromboembolic risk and the risk of disease progression among younger patients with lone AF warn us to carefully consider application of any invasive intervention that may have some adverse effects, which is especially referred to the catheter ablation $[4,6]$.

Nowadays, electrical disconnection-isolation of PVs represents a cornerstone of each AF ablative strategy. Based on the scientific evidence accumulated over the last decade, it is considered that isolation of PVs is sufficient for majority of patients with paroxysmal AF, while additional modification of LA substrate could be very important in patients with persistent $\mathrm{AF}$ [3, 19-29].

The LA is the heart chamber that is most inaccessible to catheterization. Transseptal puncture ensures access to the LA and PVs [30-33]. Today, radiofrequency current (RF) is the most often used energy source for catheter ablation of AF. RF alternating current passes through the myocardium and, due to high electrical resistance of the tissue, generates heat and causes local coagulation necrosis. By subsequent tissue scarring, electrically non-conductive barrier at the level of PV-atrial junction is created (so called electrical isolation of PVs), while resolution of oedema and inflammation from the edges of RF lesions could establish conduction through surviving myocardial fibers $[34,35]$. However, some operators prefer cryoablation, where local lesion in the atrial myocardium is created by the principle of tissue freezing [36, 37]. For application of certain energy modality different catheters can be used, designed for point-by-point ablation or shaped as single-shot devices in the form of circumferential multipolar catheter for RF ablation or balloons for cryoablation [36-39]. The ablation effects are continuously monitored by diagnostic circumferential multipolar catheter, positioned in proximal part of PV close to its ostium, which registers electrical activity inside the PV. The technique of catheter-based isolation of PVs has evolved considerably in the last decade. At the beginning, ablation was performed in segments at the level of PV ostium, whereby the local application of RF energy was guided by the earliest electrical potential of the PV at the circumferential multipolar catheter [7, 40]. However, the procedure is mostly abandoned due to its limited success and a significant risk of PV stenosis. The development of electroanatomical mapping systems provided more precise 3-dimensional catheter navigation and continuous circumferential ablation at level of the PVs antra, as presented in Figure 1. Such isolation of a wider antral region (1-2 cm from the PVs ostia) minimizes the risk of the PV damage and eliminates not only the PV-triggers, but also potential non-PV foci and rotors in the PVs antra [41-43]. In addition, (collateral) destruction of neurovegetative ganglia and reduction of the LA electrical mass may contribute to the higher efficiency of this strategy [44-46]. Most often, electrical reconnection of one or more PVs is responsible for the paroxysmal AF recurrence after the PV isolation procedure. Therefore, it is considered that in patients with paroxysmal AF, permanent ablative lesion (and isolation of all PVs) is essential and more important than any other additional set of lesions [24, 47]. However, PV isolation is a template procedure and, therefore, it may not be sufficient for specific subpopulation of patients with paroxysmal AF initiated from non-PV foci, including patients with sleep 
apnea syndrome, obese patients, women, patients with enlarged LA and older patients. In such cases, after PV isolation, non-PV triggers can be discovered by catecholamine challenge (for example, triggers in the superior caval vein), and elimination of these triggers significantly improves the clinical outcome of the procedure, as shown in Figure $2[48,49]$.

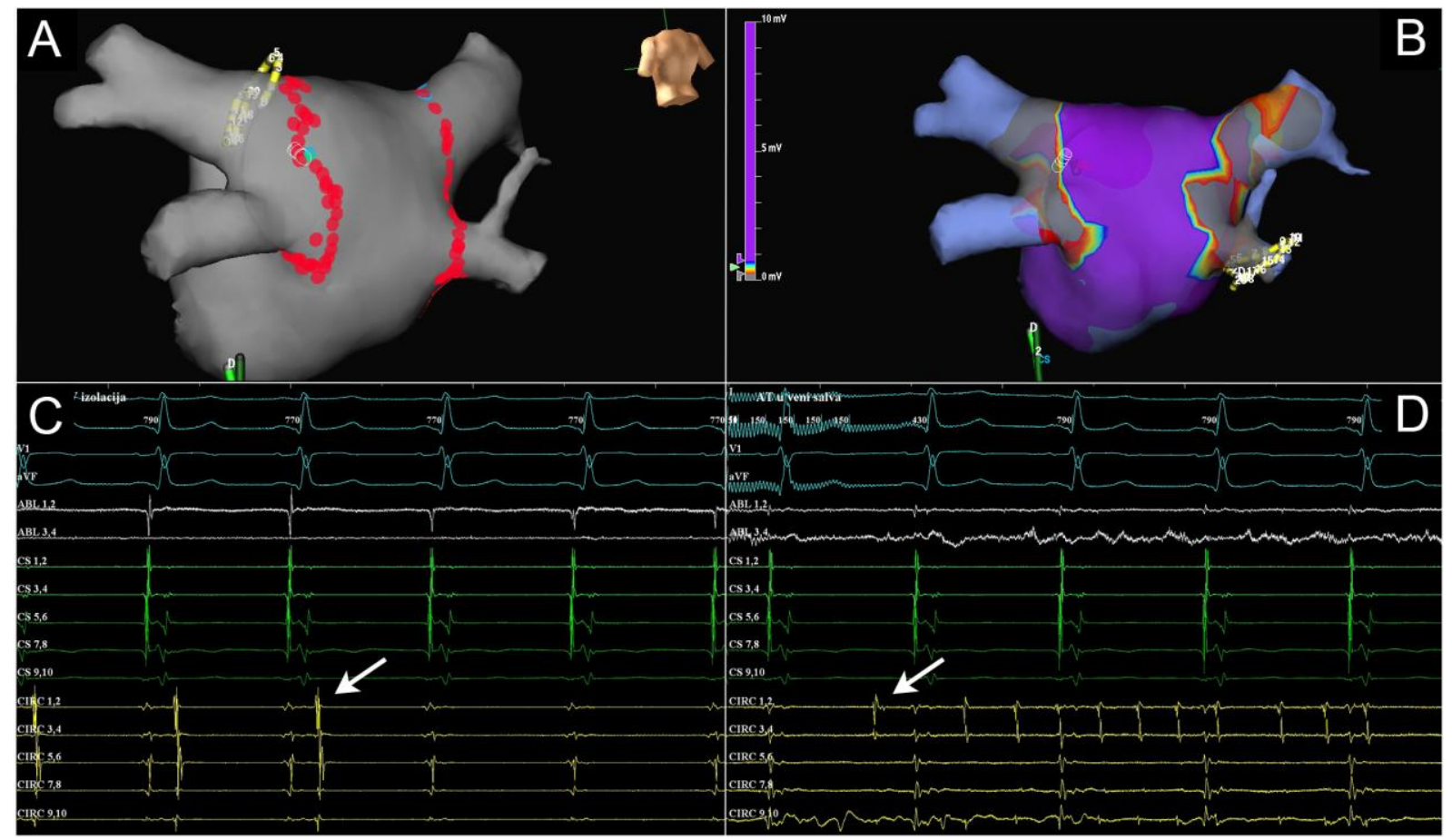

Figure 1. Catheter ablation of paroxysmal lone AF: PV isolation.

A 47-year-old male underwent catheter ablation due to a 10-year history of daily attacks of symptomatic paroxysmal lone AF, refractory to drug therapy with beta-blockers, sotalol, propafenone, and, finally flecainide. Echocardiography showed normal LA dimension $(38 \mathrm{~mm})$ and left ventricular ejection fraction $(65 \%)$. Using the electroanatomical mapping system (Ensite NavX, St Jude Medical) with CT-image integration, geometrical LA 3D-map was reconstructed and irrigation radiofrequency ablation (red dots) was performed with en-block isolation of ipsilateral PVs.

Panel A: postero-lateral LA view with circumferential antral ablation encircling left sided PVs, circumferential diagnostic (Lasso) catheter is positioned within the left superior PV.

Panel B: voltage map of LA and PVs in sinus rhythm after PV isolation. Grey and violet colors represent electrically silent regions within the PVs and electrically healthy myocardium in the remaining part of LA, respectively.

Panel C: electrical isolation of PV in sinus rhythm, with abrupt loss of PV potential recorded by circumferential diagnostic catheter (yellow signals, labeled with white arrow).

Panel D: after PV isolation, the occurrence of spontaneous repetitive short bursts of atrial tachycardia within the "arrhythmogenic" PV is recorded by the Lasso catheter (yellow signals, labeled with white arrow). However, stable sinus rhythm is maintained, due to exit PV-LA block after ablation.

During the one-year follow-up after the procedure, the patient was free of AF without drug therapy. $\mathrm{AF}=$ atrial fibrillation; $\mathrm{LA}=\mathrm{left}$ atrium; $\mathrm{CT}=$ computed tomography; $\mathrm{PV}=$ pulmonary vein . 


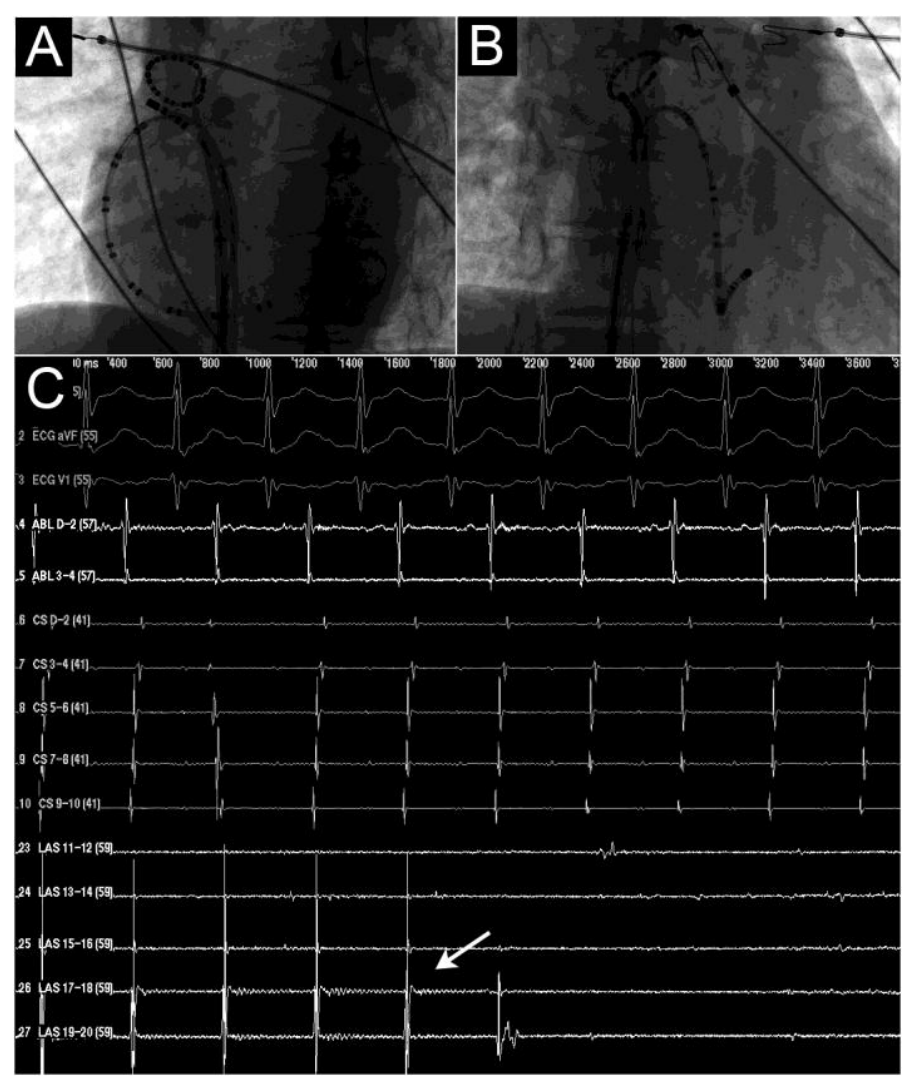

Figure 2. Catheter ablation of paroxysmal AF: elimination of non-PV triggers.

A 37-year old female patient has been referred for the second catheter ablation procedure due to highly symptomatic and frequent episodes of paroxysmal AF. In the index procedure fluoroscopically guided segmental ostial isolation of all PVs was successfully accomplished, however the patient experienced recurrence of AF in the following weeks. At the beginning of the redo procedure, all PVs were revisited and their stable electrical isolation was confirmed. Using the catecholamine challenge and pacing maneuvers, an ectopic focus in SCV was identified. Using irrigation radiofrequency catheter, electrical isolation of SCV was successfully achieved in association with AF noninducibility at the end of procedure. Over the follow up of 6 months the patient was free of symptomatic AF without antiarrhythmic drugs.

Panels A and B: fluoroscopic position of circumferential diagnostic catheter within the SCV and ablation catheter at the posterolateral aspect of SCV-atrial junction. Before RF application, high output pacing was performed to evaluate the proximity to right phrenic nerve.

Panel C: ablation at this site resulted in electrical isolation of SCV during sinus tachycardia, with elimination of SVC potentials at the Lasso catheter (white arrow).

$\mathrm{AF}=$ atrial fibrillation; $\mathrm{PV}=$ pulmonary vein; $\mathrm{SCV}=$ superior caval vein .

Among patients with persistent AF, PV isolation is most often combined with the LA substrate modification. There are three basic strategies for modification of AF substrate: LA defragmentation by ablation 
of the complex fragmented atrial electrograms (CFAE), linear ablation of LA and ganglionated plexi ablation [3, 21-29]. CFAE are the electrograms during AF which have short cycle length $(<120 \mathrm{~ms})$ or which are fractionated into two or more components, or show continuous atrial electrical activation [50]. From the electrophysiological aspect, CFAE may represent dominant rotors of AF and pivot points of microreentry, but also the sites of passive wavelet collision that are not critical for maintaining of AF. CFAE can be identified by visual inspection or automatically by dedicated software of electro-anatomical mapping system. The result of local ablation and elimination of CFAE is a prolongation of $\mathrm{AF}$ cycle length and, finally, termination of $\mathrm{AF}$ with conversion into "organized" atrial tachycardia/flutter or sinus rhythm [25, 51]. AF substrate also can be modified by the linear atrial ablation, which imitates the surgical MAZE procedure, in form of the roof line and, eventually, the inferior line on the LA posterior wall, connecting both superior and both inferior PVs. In this way, a complete electrical isolation of the whole LA posterior wall is achieved (so called "posterior box lesion"), as shown in Figure 3 [9, 52]. Linear ablation of mitral isthmus between the mitral annulus and the left inferior PV can significantly modify AF substrate [53]. Completeness and transmurality of linear lesions are very important for the successful treatment of $\mathrm{AF}$ as well as for the prevention of iatrogenic atrial tachycardia after ablation [54]. Linear ablation leads to compartmentalization of the LA and reduction of the area with CFAE, thus resulting in an additional AF cycle length increase, which can be critical for the AF termination during a stepwise approach to the ablation of longstanding persistent AF [55]. Ganglionated plexi are usually located 1-2 cm outside the LA-PV junctions at the left superolateral, right superoanterior, left inferoposterior and right inferoposterior area, and it has been shown that their anatomical RF ablation is accompanied by substantial AF substrate modification [56]. This adjunctive AF substrate modification strategy may significantly improve the midterm outcome of persistent AF catheter ablation.

AF catheter ablation outcome. Catheter ablation of AF is efficient in both short and long term rhythm control $[7,9,24,27,28,29,40-44,47,52,53,56]$. However, inconsistency in the ablation technique and technology, different definitions of success and arrhythmia recurrence and differences and limitations in the methods of clinical follow-up after the procedure complicate the realistic appreciation of the results and, therefore, it is not surprising that significant differences in outcome of AF ablation exist in the published series [3]. Besides that, the long term outcome data after ablation of AF are still scarce and limited to period of only 35 years. Early recurrences of atrial tachyarrhythmias in the first 3 months (so called "blanking period") are common (30\%-60\%) and may reflect transient inflammation of atrial tissue and immaturity of the ablative lesion. These arrhythmias can be prevented by antiarrhythmic and antiinflammatory drugs and gradually subside in $40-60 \%$ of the patients [57-59]. Therefore, final outcome of the procedure should be evaluated only after this early postoperative period.

The results of catheter ablation of lone AF are not easy to interpret, because in majority of reported series patients with lone AF are not separated from those with $\mathrm{AF}$ and minimal structural heart disease and/or comorbidities. Only few studies selected 'pure' lone AF population among young patients and athletes and showed excellent results after the first procedure with over $90 \%$ of patients being free from arrhythmia without medications, during the clinical follow-up period of more than 1-3 years [60, 61].

It has been shown that the efficacy of initial procedure was significantly higher for paroxysmal compared with persistent AF, but after multiple procedures, comparable results can be achieved in both types of AF. For acceptable long term success of ablation of $\mathrm{AF}$, multiple procedures are frequently required, which 
emphasizes the importance of creating irreversible ablative lesion in the first procedure [25, 28, 29, 47]. Indeed, the inability to create permanent and continuous ablative lesions in the first procedure represents one of the principal limits of the actual ablation technology. After achieving the PV isolation, pharmacological stimulation with adenosine and catecholamines enables wakening of dormant and partially damaged myocardial connections between the PV and LA. Subsequent ablation of these fibers can significantly increase the efficiency of the first intervention [62-64]. It seems that the loss of capture on the ablative line, ablation guided by atrial unipolar signal modification and development of contact-force technology could provide better transmurality, continuity and durability of ablative lesion [27, 65-68].

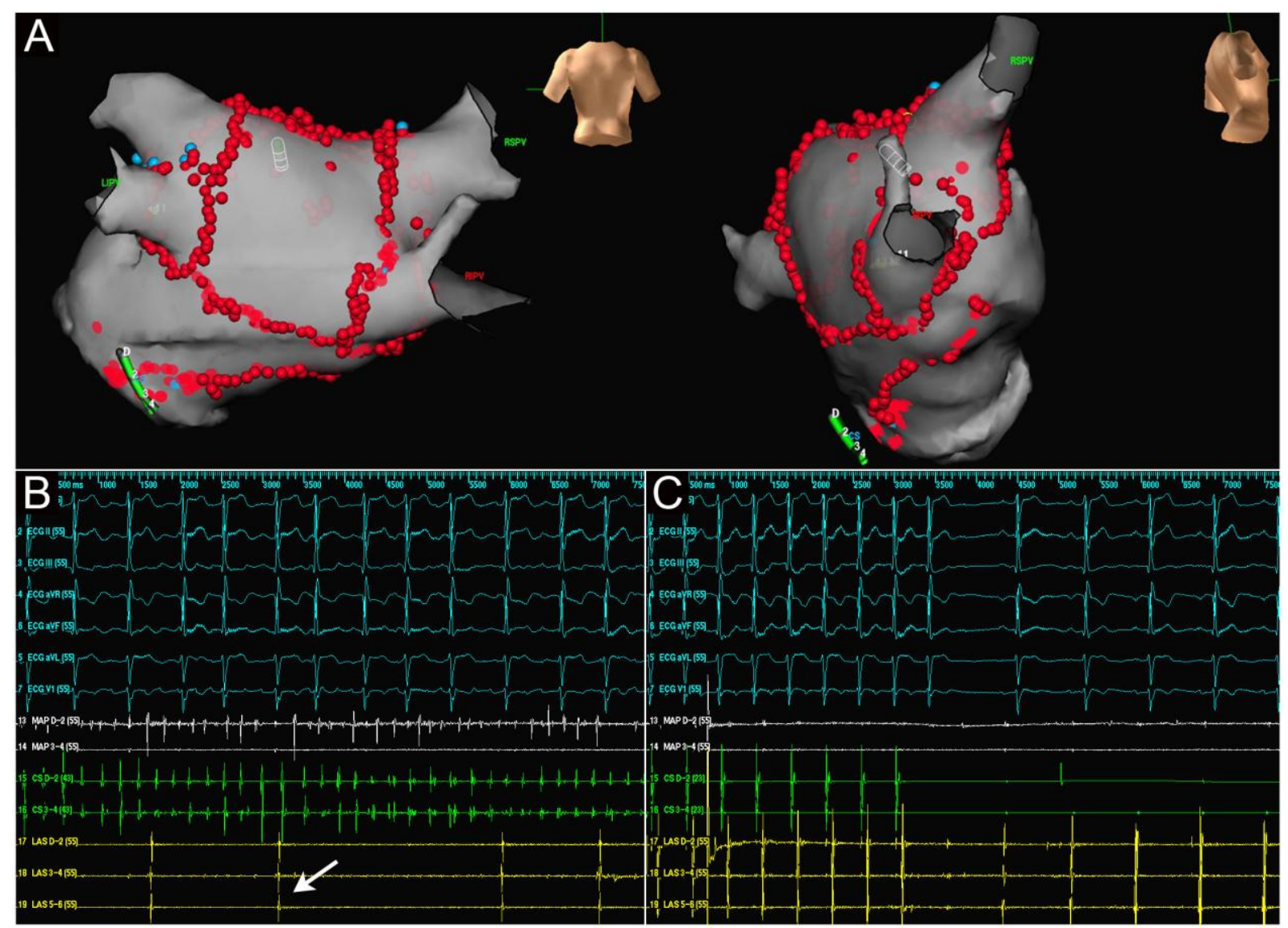

Figure 3. Catheter ablation of persistent AF: PV isolation and substrate modification.

A 57-year-old male presented with previously undiagnosed persistent $\mathrm{AF}$ with uncontrolled rate and symptoms and signs of congestive heart failure. Echocardiography revealed left ventricular systolic dysfunction with $\mathrm{EF}$ of $35 \%$ and moderate LA dilatation $(44 \mathrm{~mm})$, while coronary angiogram was normal. Treatment with amiodarone and a beta blocker as well as therapy for heart failure were instituted. Several months later he was subjected to catheter ablation of $\mathrm{AF}$, due to the clinical suspicion of tachyarrhythmia-related cardiomyopathy.

Panel A: fusion of 3D anatomical LA map with CT image (Ensite NavX, St Jude Medical), posterior LA view (left side of image) and right lateral view (right side of image). Irrigation RF ablation (red dots) included circumferential antral PV isolation coupled with LA substrate modification by means of linear ablation. Linear set consisted of roof line + inferior line ("posterior box" lesion) and endocardial linear disconnection of coronary sinus. 
Panel B: isolation of PVs during ongoing AF. Spontaneous slow automaticity within the PV was recorded (white arrow), while AF continued in the remaining part of the LA.

Panel C: during the LA linear ablation, AF has "organized" to an atrial tachycardia with fast ventricular response and further LA substrate ablation resulted in tachycardia termination with restoration of sinus rhythm. At the end of the procedure revision of all PVs and lines was performed to confirm the conduction block.

Three months following the procedure, echocardiography demonstrated complete recovery of the left ventricular systolic function (EF 60\%) and all drugs, except beta blocker, were discontinued. Over the next 12 months, the patient was free of AF.

$\mathrm{AF}=$ atrial fibrillation; $\mathrm{LA}=$ left atrium; $\mathrm{PV}=$ pulmonary vein; $\mathrm{EF}=$ ejection fraction; $\mathrm{CT}=$ computed tomography; $\mathrm{RF}=$ radiofrequency.

Recently, a meta-analysis of the large number of trials depicted the long term efficiency of single and multiple procedures of AF ablation based on the clinical follow-up period of $>3$ years [29]. The technology and strategy of AF ablation and post procedure follow-up in the included trials mostly correspond to the contemporary clinical practice. After the first procedure, long term efficiency of ablation of paroxysmal AF and persistent AF was $54.1 \%$ [95\% CI: $44.4 \%$ to $63.4 \%$ ] and $41.8 \%$ [95\% CI: $25.2 \%$ to $60.5 \%$ ]. However, multiple procedures achieved significantly better results: for paroxysmal AF 79.0\% [95\% CI: $67.6 \%$ to $87.1 \%$ ] and for persistent AF $77.8 \%$ [95\% CI: $68.7 \%$ to $84.9 \%$ ]. The average number of procedures per patient was higher for persistent than for paroxysmal AF (1.7 [95\% CI: 1.3 to 2.1] vs. 1.4 [95\% CI: 1.3 to 1.6]. Long term outcome of $\mathrm{AF}$ ablation in the studies published in the last 5 years, each of which comprised more than 100 patients, mean age of $\leq 60$ years with no or minimal organic heart disease, are presented in Table 1 [28, 47, 69-75].

There are concerns about the durability of the AF ablation effect. AF recurrences occur most often in the first year after the procedure, but longer follow-up is mandatory because there is still possibility of a later arrhythmia recurrence. Among the patients with AF recurrence, the arrhythmia occurred in $66 \%$ of them in the first 6 months, in $76 \%$ in the first year and even in $88 \%$ in the first 2 years after the procedure [76]. Although some studies confirmed low rates of late AF recurrences (only $8.9 \%$ to $16 \%$ at $>1$ year after the procedure) and showed that AF ablation has a quite long effect (in 5-year-follow-up even 71\% of patients remained in stable sinus rhythm), other studies pointed towards the disturbing fact that among patients who did not have the arrhythmia in the first year after AF ablation, a progressive increase in the rate of late AF recurrences could be expected [74, 77-79]. Such studies reported cumulative rates of late AF recurrences after the first year post ablation: after 2 years the rate was $13 \%$, after 3 years $22 \%$, after 4 years it was $35 \%$, after 5 years $47 \%$ and after 6 years 55\% [79]. While the most common finding at repeated electrophysiological study among the patients with AF recurrence within the first year after ablation was the PV reconnection, the appearance of late AF recurrences can be related not only to reconnection of the PVs but also to the development of non-PV triggers of $\mathrm{AF}$ and evolution of the AF substrate, especially among the older patients with structural heart disease and comorbidities $[76,78,80]$. Numerous pre-procedural clinical predictors of AF recurrence are identified, such as: the LA dilatation, early recurrence of atrial tachyarrhythmia (during the "blanking" period), previous history of persistent AF, the presence of structural heart disease, hypertension, hyperlipidemia, sleep apnoea, older age, 
obesity, biochemical markers of inflammation, atrial fibrosis on MRI and increased $\mathrm{CHADS}_{2}$ and $\mathrm{CHA}_{2} \mathrm{DS}_{2}$ VAS $_{C}$ score $[18,74,80-84]$. Therefore, among younger patients with lone AF and normal or minimally remodelled LA, not only higher efficiency but also more stable long term effects of catheter ablation can be expected. Thus, after RF catheter ablation procedures with PV isolation performed in middle-aged athletes with idiopathic AF (mean age 44 years), $90 \%$ of the patients were free of AF at 3-year follow-up [61]. Similarly, after the PV isolation using cryoballoon technique, symptomatic AF was eliminated in $89 \%$ of younger patients (mean age 44 years, $83 \%$ males) with lone AF and normal size of the LA during the period of 14 months after the procedure [60].

Some of the patients with AF recurrence respond well to the AAD, which was not efficient before the procedure, and in such cases new procedure is not obligatory. Among these patients, repeated electrophysiological study performed 3 months after the index ablation revealed reconnection with substantial atrio-PV delay of conduction. Moreover, AADs may additionally slow conduction, causing an exit block from the PV(s) and successfully controlling AF initiation [85].

Ablation versus drugs for lone AF. The presence of AF doubles the mortality and morbidity and it increases risk of ischemic stroke by fivefold $[1,2]$. On the other hand, long term prognosis of lone AF is favourable and significantly better in comparison with patients with non-lone AF. During the long term followup period of 12 years, $27 \%$ of the patients with newly diagnosed paroxysmal lone AF progressed towards permanent AF with low rate of mortality (1.4\%), thromboembolism (0.4\%) and HF (0.4\%). However, progression to permanent $\mathrm{AF}$, aging and subsequent development of underlying heart disease among patients with initially paroxysmal lone AF were independent predictors of adverse cardiovascular events, including systemic thromboembolism and HF [86].

Randomized controlled trials failed to demonstrate benefits of the maintenance of sinus rhythm with AADs in comparison to the pharmacological control of ventricular rate in patients with AF [87-89]. Indeed, both pharmacological strategies (i.e., rhythm control and rate control) showed comparable rates of mortality and stroke among patients with AF. However, subsequent sub-analysis showed that sinus rhythm was associated with a survival increase of $47 \%$ compared with AF, whilst the use of AADs was associated with a $49 \%$ increase in mortality. Thus, the advantages of sinus rhythm over AF were annulled by the adverse effects of AADs used for prevention of the arrhythmia [87-89]. Catheter ablation of AF provides a possibility to maintain sinus rhythm without the use of AADs in the large proportion of selected patients with AF, and it represents a promising alternative to available pharmacological therapy for rhythm control.

Table 2 presents several randomized studies which compared efficiency and safety of AADs versus catheter ablation for the treatment of patients with AF [90-99]. Clinical follow-up in these studies most often was 1 year, whilst only one study reported long term results. Most of the studies included population of younger AF patients with low prevalence of structural heart disease. Seven trials analyzed efficacy of ablation and antiarrhythmic therapy in the treatment of AF refractory to at least one "true" class I (i.e. propafenone, flecainide and disopyramide) or class III AAD (i.e. sotalol, amiodarone and dofetilide) [91-97, 99]. In addition, two studies compared the results of transcatheter and pharmacological therapy as the first therapeutic option in patients with previously untreated AF [90, 98]. Freedom from atrial tachyarrhythmias was registered significantly more often after catheter ablation than with drug therapy (74\% vs. $25 \%$ ). In the studies, which included mostly patients with paroxysmal AF, the efficacy of ablation was $63-85 \%$ with single, and $85-89 \%$ with multiple ablation procedures. 
Table 1. Studies on long term outcome following catheter ablation of atrial fibrillation in patients with no or minimal structural disease.

\begin{tabular}{|c|c|c|c|c|c|c|c|c|c|c|c|c|c|}
\hline $\begin{array}{l}\text { Year of } \\
\text { the study }\end{array}$ & $\begin{array}{l}\text { № } \\
\text { pts }\end{array}$ & $\begin{array}{c}\text { Age } \\
\text { (years) }\end{array}$ & Males & PAF & $\begin{array}{l}\text { Lone } \\
\text { AF }\end{array}$ & SHD & Co-MBD & $\begin{array}{c}\mathrm{LA} \\
(\mathrm{mm})\end{array}$ & $\begin{array}{l}\text { Ablation } \\
\text { strategy }\end{array}$ & $\begin{array}{c}\text { Redo } \\
\text { ablation }\end{array}$ & $\begin{array}{l}\text { Follow-up } \\
\text { (months) }\end{array}$ & $\begin{array}{c}\text { Freedom of } A F \\
\text { (multiple ablations } \\
+ \text { AAD) }\end{array}$ & AADs \\
\hline 2008 [69] & 139 & 55 & $78 \%$ & $100 \%$ & $42 \%$ & $7 \%$ & NA & 41 & $\begin{array}{l}\text { RF } 8 \mathrm{~mm}, \\
\text { PVI ostial }\end{array}$ & $22 \%$ & 33 & $58 \%$ & $23 \%$ \\
\hline 2008 [70] & 110 & 52 & $80 \%$ & $100 \%$ & NA & - & $52 \%$ (HTA) & 39 & $\begin{array}{c}\text { RF } 4 \text { mm, EAM } \\
\text { PVI ostial vs.PVAI }\end{array}$ & $34 \%$ & 48 & $89 \%$ vs. $91 \%$ & $10 \%$ \\
\hline 2008 [28] & 204 & 55 & $79 \%$ & $61 \%$ & NA & $14 \%$ & NA & $42-49$ & $\begin{array}{l}\text { RF irrigation, EAM, } \\
\text { PVAl vs. PVAI+lines }\end{array}$ & $\begin{array}{l}\text { 40\% (PAF) } \\
54 \% \text { (PeAF) }\end{array}$ & 41 & $\begin{array}{l}62 \% \text { vs. } 85 \% \text { (PAF) } \\
39 \% \text { vs } 75 \% \text { (PeAF) }\end{array}$ & - \\
\hline 2010 [47] & 161 & 60 & $75 \%$ & $100 \%$ & NA & $20 \%$ & $\begin{array}{c}67 \% \text { (HTA) } \\
5 \% \text { (DM) }\end{array}$ & 43 & $\begin{array}{l}\text { RF irrigation, } \\
\text { EAM-PVAI }\end{array}$ & $41 \%$ & 55 & $79 \%$ & $15 \%$ \\
\hline 2011 [71] & 100 & 54 & $79 \%$ & $100 \%$ & NA & $6 \%$ & $\begin{array}{c}27 \% \text { (HTA) } \\
2 \%(\mathrm{DM})\end{array}$ & 42 & $\begin{array}{l}\text { RF irrigation, } \\
\text { EAM-PVAI }\end{array}$ & $22 \%$ & 39 & $82 \%$ & $30 \%$ \\
\hline 2011 [72] & 260 & 54 & $90 \%$ & $61 \%$ & NA & $9 \%$ & $28 \%$ (HTA) & 39 & $\begin{array}{c}\text { RF } 8 \text { mm, } \\
\text { EAM-PVAl (+CFAE) }\end{array}$ & $27 \%$ & 30 & $95 \%$ & - \\
\hline 2011 [73] & 100 & 56 & $86 \%$ & $63 \%$ & NA & $36 \%$ & $\begin{array}{c}43 \%(\mathrm{HTA}) \\
3 \%(\mathrm{DM})\end{array}$ & NA & $\begin{array}{c}\text { RF irrigation, } \\
\text { PVI ostial (+lines) }\end{array}$ & $51 \%$ & 54 & $63 \%$ & NA \\
\hline 2011 [74] & 831 & 59 & $77 \%$ & $69 \%$ & NA & $14 \%$ & $\begin{array}{l}\text { 35\% (HTA) } \\
8 \%(\mathrm{DM})\end{array}$ & NA & $\begin{array}{c}\text { RF irrigation, } \\
\text { ICE-PVAI (+SVC) }\end{array}$ & $23 \%$ & 55 & $90 \%$ & $12 \%$ \\
\hline 2013 [75] & 605 & 59 & $77 \%$ & $96 \%$ & $46 \%$ & $12 \%$ & $42 \%(\mathrm{HTA})$ & 42 & $\begin{array}{l}\text { Cryo-balloon } \\
\text { (+RF irrigation) }\end{array}$ & $18 \%$ & 33 & $77 \%$ & NA \\
\hline
\end{tabular}

Abbreviations:

$\mathrm{PAF}=$ paroxysmal AF; $\mathrm{AF}=$ atrial fibrillation; $\mathrm{SHD}=$ structural heart disease; $\mathrm{Co}-\mathrm{MBD}=$ comorbidities; $\mathrm{LA}=\mathrm{left}$ atrium; $\mathrm{AAD}=$ antiarrhythmic drugs; $\mathrm{NA}=\mathrm{not}$ available;

$\mathrm{RF}=$ radiofrequency; $\mathrm{PVI}=$ pulmonary vein isolation; HTA=hypertension; $\mathrm{EAM}=$ electro-anatomical mapping system; $\mathrm{PVAI}=$ pulmonary vein antral isolation; PeAF=persistent $\mathrm{AF}$; DM=diabetes mellitus; $\mathrm{CFAE}=$ complex fragmented atrial electrograms; $\mathrm{ICE}=$ intracardiac echocardiography; $\mathrm{SVC}=$ superior vena $\mathrm{cava}$. 
On the other hand, among patients with paroxysmal AF refractory to previous pharmacological therapy, successful maintenance of sinus rhythm by changing the AAD was achieved in only 9-23\% of patients [91, 93, $95,96]$. However, among patients with previously untreated paroxysmal AF, AADs successfully prevented the occurrence of arrhythmia in as many as $71 \%$ of patients [98]. Indeed, it was shown that the failure of prior AAD therapy predicts the failure of subsequent attempts to pharmacologically control the rhythm and that the administration of alternative drug can effectively prevent AF only in a small portion of the patients $[91,93,95$, 96]. Overall, the superiority of catheter ablation over pharmacological treatment is the most evident in patients with paroxysmal AF who failed AAD therapy. Recently, a randomized study showed that even among patients with persistent AF, catheter ablation is more efficient for rhythm control in comparison to medical therapy. At one-year follow-up, $60 \%$ of patients were free of AF after the procedure (36\% of them were also taking an $\mathrm{AAD}$ ) in comparison to $29 \%$ of patients treated with AADs only [99]. In addition, it has been demonstrated that after a failure of the initial PV isolation in patients with paroxysmal AF, a repeated AF ablation was significantly more effective than AAD therapy in control of $\mathrm{AF}(58 \%$ vs. $12 \%$, p<0.01) [100]. Besides that, during the oneyear follow up, AAD therapy was more often associated with side effects compared to invasive treatment (17\% vs. $8 \%$ ) [101]. A meta-analysis of 8 randomized trials with total of 844 patients confirmed safety of catheter ablation. Fewer adverse effects were registered among patients treated with AF ablation than in those treated with AADs (RR 0.72 [95\% CI: 0.40 to 1.30 ]; $\mathrm{p}=0.28$ ) [102].

\section{Potential benefits of AF ablation}

Survival and thromboembolism. AF is associated with significant increase in mortality and risk of stroke $[1,2]$. Therefore, it is expected that proven superiority of a non-pharmacological method (which offers the possibility of curing AF) over potentially dangerous medical therapy could be transferred to the reduction of rates of "hard endpoints" such as mortality and systemic thromboembolism.

However, the meta-analysis of 8 randomized studies did not find significant differences in mortality rate and rate of cerebrovascular events between patients treated by catheter ablation (486 patients) and by AADs (444 patients) [103]. The mean age of patients was 51 to 64 years, with low prevalence of structural heart disease of $4 \%$ to $24 \%$ (only in one study the prevalence of underlying heart disease was higher, reaching about $50 \%$ of participants). During the one-year follow up of patients treated with catheter ablation and AADs, 3 and 4 deaths $(\mathrm{p}=0.74)$, and 3 and 1 cerebrovascular events $(\mathrm{p}=0.54)$, respectively, were reported [103]. In these studies, low mortality and cerebrovascular event rates in both subgroups of patients could be the result of the selection of low-risk AF population with high prevalence of lone $\mathrm{AF}$ and short follow-up after the intervention.

On the other hand, several nonrandomized trials, which mainly analyzed "sicker and older" AF population, demonstrated a beneficial effect of ablation to the survival of patients with AF. In the study where prevalence of cardiovascular and lung disease was 58\% and the mean age was 65 years, mortality was significantly reduced (6\% vs. $14 \%$ ) as well as the rate of cerebrovascular events ( $2 \%$ vs. $8 \%$ ) among the patients treated by catheter ablation compared to AAD therapy, respectively, during the follow-up of 2.5 years [104]. 
Another study also included high-risk AF patients with mean age of about 67 years (median 69 years) and $\geq 1$ risk factor for stroke, who were followed up for 2.3 years. The mortality rate after catheter ablation was significantly lower compared to antiarrhythmic drug treatment (3\% vs. $12 \%$ ) and sinus rhythm was the strongest factor associated with the reduction of mortality rate (HR 0.14 [95\% CI: 0.06 to 0.36 ], p<0.0001) [105]. In addition, an international multicenter registry encompassed 1273 patients (mean age of 58 years, an average $\mathrm{CHADS}_{2}$ score of 0.7), who underwent catheter ablation of AF [106]. Their outcomes were compared with a cohort of AF patients treated medically and a hypothetical cohort without AF, age and gender matched to the study group (total of 5333 patients). Stroke rate ( $2.8 \%$ vs. $0.5 \%$ per patient year) and mortality rate (5.3\% vs. $0.5 \%$ per patient year) were significantly lower among the patients treated by catheter ablation of AF. Freedom from $\mathrm{AF}$ after the procedure was a significant predictor of stroke-free survival (HR 0.33 [95\% CI: 0.17 to 0.67]; $\mathrm{p}=0.002$ ) [106]. A recent study reported that during a 4-year follow-up of 953 patients (mean age 57 years) with $\mathrm{AF}$ and an increased $\mathrm{CHA}_{2} \mathrm{DS}_{2}$-VASc score of $\geq 1$, total mortality (11.5\% vs. $\left.2.9 \%\right)$ as well as central and/or peripheral vascular thromboembolism ( $8.6 \%$ vs. $2.3 \%)$ were considerably lower among patients treated with catheter ablation in comparison to patients treated pharmacologically, respectively [107]. Moreover, among the patients treated with catheter ablation, the recurrence of $\mathrm{AF}$ was an independent predictor of severe cardiovascular (HR 2.63 [95\% CI: 1.15 to 5.9]; p=0.02) and thromboembolic vascular events (HR 2.52 [95\% CI: 1.05 to 6.06]; $p=0.04$ ) [107]. Therefore, the more beneficial effect of catheter ablation on survival and systemic thromboembolism (in relation to medical therapy) could be expected in high risk population of older AF patients with structural heart disease and increased thromboembolic risk, as compared to the low risk younger patients with lone AF and generally favourable prognosis.

Progression of AF. The rate of progression of paroxysmal to persistent AF increases with multiplication of well-known risk factors such as hypertension, aging, history of previous transitory ischemic attack (TIA) or stroke, chronic obstructive lung disease and HF (so called HATCH score). Depending on presence and number of risk factors, the rate of $\mathrm{AF}$ progression among unselected population of patients with paroxysmal AF ranges from 6\% to 50\% during the first year of follow-up [108]. In contrast with these findings, among younger patients with paroxysmal and "truly" lone AF, 10-year-cummulative rate of progression towards permanent AF was only $19.1 \%$ (95\% CI: 12.8 to $25.4 \%$ ) [86]. In another long term study, paroxysmal and persistent lone AF have progressed to permanent form of the arrhythmia with 30-year cumulative probability of 29\% (95\% CI: 16 to 42\%) [109]. While aging of the patients and subsequent development of structural heart disease and other comorbidities were associated with the risk of progression of lone AF, the progression of lone $\mathrm{AF}$ itself was an independent predictor of adverse events such as thromboembolism [86]. Catheter ablation of paroxysmal AF might delay further progression of the disease. After ablation of paroxysmal AF, the progression of AF was evident among $1.5 \%$ of the patients during the follow-up of 27 months, with annual incidence of $0.6 \%$ [110]. However, among patients treated medically, the progression rate of paroxysmal AF was markedly higher, reaching $8.6 \%$ in the first year and $24.7 \%$ after 5 years [111]. Since the result of catheter ablation is significantly better for paroxysmal $\mathrm{AF}$ than for persistent $\mathrm{AF}$, with lower recurrence rates and simpler procedure (most often limited only to $\mathrm{PV}$ isolation) in the former, the question arises about preventive ablation of paroxysmal $\mathrm{AF}$ in selected patients in order to slow down the progression of $\mathrm{AF}$ and reduce the potential risks of such disease progression. 
Table 2. Randomized studies that compared the antiarrhythmic drugs and catheter ablation for the treatment of atrial fibrillation.

\begin{tabular}{|c|c|c|c|c|c|c|c|c|c|c|c|c|c|c|c|}
\hline \multirow[t]{2}{*}{ Year } & \multirow{2}{*}{$\begin{array}{l}\text { № } \\
\text { pts }\end{array}$} & \multirow{2}{*}{$\begin{array}{l}\text { Age } \\
\text { (years) }\end{array}$} & \multirow[t]{2}{*}{ Study design } & \multirow{2}{*}{$\begin{array}{l}\mathrm{AF} \\
\text { type }\end{array}$} & \multirow[t]{2}{*}{ SHD } & \multirow{2}{*}{$\begin{array}{l}\text { LA } \\
(\mathrm{mm})\end{array}$} & \multirow{2}{*}{$\begin{array}{l}\text { Ablation } \\
\text { strategy }\end{array}$} & \multirow{2}{*}{$\begin{array}{l}\text { AAD } \\
\text { strategy }\end{array}$} & \multirow{2}{*}{$\begin{array}{l}\text { Follow- } \\
\text { up } \\
\text { (months) }\end{array}$} & \multicolumn{3}{|c|}{ Ablation results } & \multicolumn{3}{|c|}{ AAD results } \\
\hline & & & & & & & & & & $\begin{array}{c}\text { Freedom of } \\
\text { AF }\end{array}$ & $\begin{array}{l}\text { Cross- } \\
\text { over to } \\
\text { AADs }\end{array}$ & Adverse events & $\begin{array}{c}\text { Freedom of } \\
\text { AF }\end{array}$ & $\begin{array}{l}\text { Cross- } \\
\text { over to } \\
\text { ablation }\end{array}$ & Adverse events \\
\hline $\begin{array}{l}2005 \\
{[90]}\end{array}$ & 70 & $\approx 54$ & $\begin{array}{l}\text { First line therapy } \\
\text { for AF: } \\
\text { ablation vs. AADs }\end{array}$ & $\begin{array}{l}96 \% \\
\text { PAF }\end{array}$ & $26 \%$ & $\approx 42$ & $\begin{array}{l}\text { RF, } 8 \mathrm{~mm}, \\
\text { ICE-PVI }\end{array}$ & $\begin{array}{l}77 \% \text { flecainide } \\
23 \% \text { sotalol } \\
5 \% \text { amiodarone }\end{array}$ & 12 & $85 \%$ & $3 \%$ & $\begin{array}{c}3 \% \\
\text { (PV stenosis) }\end{array}$ & $21 \%$ & $51 \%$ & $\begin{array}{c}9 \% \\
\text { (bradycardia) }\end{array}$ \\
\hline $\begin{array}{l}2006 \\
{[91]}\end{array}$ & 137 & 62 & $\begin{array}{l}\text { AF refractory to } \\
\geq 1 \text { AAD: } \\
\text { ablation+AAD vs. } \\
\text { „new“ AAD }\end{array}$ & $\begin{array}{l}67 \% \\
\text { PAF }\end{array}$ & $63 \%$ & $\approx 45$ & $\begin{array}{c}\mathrm{RF}, 8 \mathrm{~mm} \text { or } \\
\text { irrigated-tip, } \\
\text { EAM-CPVA } \\
\quad \pm \text { lines })\end{array}$ & $\begin{array}{l}62 \% \text { amiodarone } \\
26 \% \text { flecainide } \\
10 \% \text { propafenone } \\
6 \% \text { sotalol } \\
1 \% \text { disopyramide }\end{array}$ & 12 & $56 \%$ & - & $\begin{array}{c}4 \% \\
(1 \mathrm{CVI}, \\
1 \text { tamponade, } \\
1 \text { phrenic nerve } \\
\text { palsy) }\end{array}$ & $9 \%$ & $57 \%$ & $\begin{array}{c}3 \% \\
(1 \mathrm{SCD}, 1 \mathrm{TIA})\end{array}$ \\
\hline $\begin{array}{l}2006 \\
{[92]}\end{array}$ & 146 & 57 & $\begin{array}{c}\text { PeAF>6 m: } \\
\text { amiodarone vs. } \\
\text { ablation } \\
\end{array}$ & $\begin{array}{l}100 \% \\
\text { PeAF }\end{array}$ & $8 \%$ & 45 & $\begin{array}{c}\text { RF, } 8 \mathrm{~mm}, \\
\text { EAM-CPVA } \\
( \pm \text { lines }) \\
\end{array}$ & $\begin{array}{l}\text { 100\% amiodarone } \\
\text { (first } 3 \text { months) }\end{array}$ & 12 & $74 \%$ & $1 \%$ & - & $4 \%$ & $77 \%$ & - \\
\hline $\begin{array}{l}2008 \\
{[93]}\end{array}$ & 112 & 51 & $\begin{array}{c}\text { PAF refractory to } \\
\geq 1 \text { AAD: } \\
\text { ablation vs. } \\
\text { „new“ AAD }\end{array}$ & $\begin{array}{l}100 \% \\
\text { PAF }\end{array}$ & $26 \%$ & 40 & $\begin{array}{l}\text { RF, irrigated- } \\
\text { tip, } \\
\mathrm{PVI}( \pm \text { non } \\
\mathrm{PV} \text { triggers })\end{array}$ & $\begin{array}{l}83 \% \text { Class I } \\
76 \% \text { Class III } \\
\text { (59\% amiodarone) }\end{array}$ & 12 & $\begin{array}{c}89 \% \\
(1.8 \\
\text { procedures/ } \\
\text { pt.) }\end{array}$ & $9 \%$ & $\begin{array}{c}3 \% \\
\text { (155 procedures: } \\
2 \text { tamponades, } \\
2 \text { hematomas, } \\
1 \text { PV stenosis) }\end{array}$ & $23 \%$ & $63 \%$ & $\begin{array}{c}2 \% \\
(1 \text { hypothyreosis }) \\
+ \\
2 \text { unrelated deaths }\end{array}$ \\
\hline $\begin{array}{l}2009 \\
{[94]}\end{array}$ & 70 & $\approx 64$ & $\begin{array}{c}\text { AF refractory to } \\
\geq \mathrm{AAD} \text { : } \\
\text { ablation vs. } \\
\text { „new“ AAD }\end{array}$ & $\begin{array}{l}41 \% \\
\text { PAF }\end{array}$ & $50 \%$ & 45 & $\begin{array}{l}\text { RF, irrigated- } \\
\text { tip, } \\
\text { EAM-PVAI } \\
( \pm \text { lines })\end{array}$ & $\begin{array}{l}77 \% \text { Class IC } \\
63 \% \text { amiodarone } \\
9 \% \text { sotalol }\end{array}$ & 12 & $80 \%$ & - & $\begin{array}{c}3 \% \\
\text { (1 hematoma) }\end{array}$ & $43 \%$ & - & $\begin{array}{c}17 \% \\
(5 \text { bradycardias, } \\
1 \mathrm{AFL})\end{array}$ \\
\hline $\begin{array}{l}2010 \\
{[95]}\end{array}$ & 167 & 56 & $\begin{array}{l}\text { PAF refractory to } \\
\geq 1 \text { AAD: } \\
\text { ablation+AAD vs. } \\
\text { „new“ AAD }\end{array}$ & $\begin{array}{l}100 \% \\
\text { PAF }\end{array}$ & $11 \%$ & 40 & $\begin{array}{l}\text { RF, irrigated- } \\
\text { tip } \\
\text { EAM-PVAI } \\
\text { ( } \pm \text { lines or } \\
\text { CFAE) }\end{array}$ & $\begin{array}{l}41 \% \text { propafenone } \\
36 \% \text { flecainide } \\
20 \% \text { sotalol } \\
4 \% \text { dofetilide }\end{array}$ & 9 & $63 \%$ & $7 \%$ & $\begin{array}{c}5 \% \\
\text { (2 CHF, } \\
1 \text { pericardial } \\
\text { effusion, } \\
1 \text { vascular } \\
\text { complications, } \\
1 \text { pneumonia) } \\
\end{array}$ & $17 \%$ & $76 \%$ & $\begin{array}{c}9 \% \\
\text { (2 proarrhythmia, } 3 \\
\text { intolerance) }\end{array}$ \\
\hline $\begin{array}{c}2006 \\
{[96]} \\
\& \\
2011 \\
{[97]}\end{array}$ & 198 & 56 & $\begin{array}{c}\text { PAF refractory to } \\
\quad \geq 1 \text { AAD: } \\
\text { ablation vs. } \\
\text { „new“ AAD }\end{array}$ & $\begin{array}{l}100 \% \\
\text { PAF }\end{array}$ & $\approx 6 \%$ & $\approx 39$ & $\begin{array}{c}\text { RF, } 8 \text { mm or } \\
\text { irrigated-tip, } \\
\text { EAM-CPVA } \\
( \pm \text { lines })\end{array}$ & $\begin{array}{l}\text { 33\% flecainide } \\
33 \% \text { sotalol } \\
33 \% \text { amiodarone }\end{array}$ & 48 & $72 \%$ & - & $\begin{array}{c}5 \% \\
\text { (3 AT, } \\
1 \text { pericardial } \\
\text { effusion, } \\
1 \text { TIA) }\end{array}$ & $12 \%$ & $88 \%$ & $\begin{array}{c}68 \% \\
\text { (19 hyperthyreosis, } \\
15 \text { bradycardia, } 11 \\
\text { sexual dysfunction, } \\
10 \text { wide QRS, } 2 \\
\text { visual and }\end{array}$ \\
\hline
\end{tabular}




\begin{tabular}{|c|c|c|c|c|c|c|c|c|c|c|c|c|c|c|c|}
\hline & & & & & & & & & & & & & & & $\begin{array}{c}\text { dermatological } \\
\text { events, } 1 \text { hepatitis) }\end{array}$ \\
\hline $\begin{array}{l}2012 \\
{[98]}\end{array}$ & 294 & 55 & $\begin{array}{l}\text { First line therapy } \\
\text { for PAF: } \\
\text { ablation vs. AADs }\end{array}$ & $\begin{array}{l}100 \% \\
\text { PAF }\end{array}$ & $10 \%$ & 40 & $\begin{array}{c}\mathrm{RF}, 8 \mathrm{~mm} \text { or } \\
\text { irrigated-tip, } \\
\text { EAM-PVAI } \\
\quad \pm \text { lines })\end{array}$ & $\begin{array}{l}88 \% \text { Class IC } \\
10 \% \text { Class III }\end{array}$ & 24 & $\begin{array}{c}85 \% \\
(1.6 \\
\text { procedures/ } \\
\text { pt. })\end{array}$ & $9 \%$ & $\begin{array}{c}14 \% \\
\text { (1 CVI-death, } \\
1 \text { SCD, } \\
3 \text { tamponades, } \\
1 \text { CVI, } 1 \text { TIA, } \\
1 \text { PV stenosis, } \\
3 \text { AFL) }\end{array}$ & $71 \%$ & $36 \%$ & $\begin{array}{c}11 \% \\
(1 \mathrm{SCD} \\
5 \mathrm{AFL})\end{array}$ \\
\hline $\begin{array}{l}2013 \\
{[99]}\end{array}$ & 146 & 55 & $\begin{array}{c}\operatorname{PeAF}(<1 \text { year }) \\
\text { refractory to } \geq 1 \\
\text { AAD: } \\
\text { ablation vs. AAD }\end{array}$ & $\begin{array}{l}100 \% \\
\text { PeAF }\end{array}$ & $\approx 3 \%$ & $\approx 42$ & $\begin{array}{l}\text { RF, irrigated- } \\
\text { tip, } \\
\text { EAM-PVAI } \\
( \pm \text { lines or } \\
\text { CFAE })\end{array}$ & $\begin{array}{l}44 \% \text { Class IC } \\
\text { (flecainide) } \\
56 \% \text { Class III } \\
\text { (amiodarone) }\end{array}$ & 12 & $\begin{array}{c}60 \% \\
\text { (8\% redo) }\end{array}$ & $36 \%$ & $\begin{array}{c}6 \% \\
\text { (2 pericarditis, } \\
1 \text { pericardial } \\
\text { effusion, } \\
3 \text { vascular } \\
\text { complications) }\end{array}$ & $29 \%$ & $\begin{array}{c}0 \% \\
(48 \%)\end{array}$ & $\begin{array}{c}2 \% \\
\begin{array}{c}\text { (1 intoxication with } \\
\text { flecainide) }\end{array}\end{array}$ \\
\hline
\end{tabular}

Abbreviations:

CPVA=circumferential pulmonary vein ablation; $\mathrm{SCD}=$ sudden cardiac death; $\mathrm{TIA}=$ transitory ischemic attack; $\mathrm{CHF}=$ congestive heart failure; $\mathrm{AT}=$ atrial tachycardia; $\mathrm{AFL}=$ atrial flutter.

Other abbreviations as in table 1. 
Heart failure. AF and HF often coexist, because they share common risk factors such as aging, hypertension, diabetes, obesity, valvular, ischemic and non-ischemic structural heart disease. The prevalence of $\mathrm{AF}$ increases with the severity of $\mathrm{HF}$ and it ranges from $5 \%$ in patients with mild up to $50 \%$ in patients with severe HF [112]. Sometimes it is not easy to define the cause and the consequence among patients clinically presenting with AF and HF. AF associated with fast and uncontrolled ventricular response is the most common cause of tachycardia-induced cardiomyopathy and low-output HF [1]. Pathophysiology of tachycardia-induced cardiomyopathy is not elucidated completely, but myocardial ischemia, depletion of myocardial energy and abnormalities of intracellular transport of calcium probably play important role [113]. The true prevalence of this secondary myocardial dysfunction among the patients with $\mathrm{AF}$ and $\mathrm{HF}$ is not known, but it is estimated that about $10 \%$ of the patients have "pure" tachy-cardiomyopathy, while among $25 \%$ up to $50 \%$ of the patients there is some component of tachycardia-related HF [113]. It is very important to maintain a high level of suspicion for tachycardia-induced cardiomyopathy in patients with $\mathrm{AF}$ and $\mathrm{HF}$, because if tachyarrhythmia is the primary cause of HF, the restoration of sinus rhythm may lead to complete or significant improvement of systolic left ventricular function. In fact, tachycardia-induced cardiomyopathy is presently the most common unrecognized but potentially reversible cause of $\operatorname{HF}[1,3,112,113]$. During the evaluation of patients with $\mathrm{AF}$ and nonischemic cardiomyopathy one should bear in mind the possible clinical scenario in which the progression of paroxysmal to persistent lone $\mathrm{AF}$, associated with rapid ventricular rate, could be responsible for secondary left ventricular myocardial dysfunction. Since the medical therapy of AF in patients with HF is limited due to potentially negative inotropic and proarrhythmic effects of the drugs, catheter ablation of AF emerges as an attractive therapeutic option.

In the research that included 299 patients with normal and 67 patients with reduced left ventricular ejection fraction (EF) $\leq 50 \%$ and AF, longitudinal echocardiographic study was conducted [114]. At 6 months after the catheter ablation of AF, among the patients with myocardial dysfunction significant recovery of EF from $42 \%$ before to $56 \%$ after the procedure was reported. The success of the catheter ablation treatment was similar among the patients with reduced and normal EF ( $86 \%$ vs. $87 \%$ ) but at the cost of higher number of repeated procedures in patients with left ventricular systolic dysfunction (1.6 vs. 1.3 procedures per patient). These findings were in line with the results of another study that demonstrated favourable effect of ablation on myocardial function among 58 patients (mean age 56 years) with congestive HF, average baseline EF of 35\% and predominantly persistent and permanent AF [115]. At the end of the first year following the procedure, a similar proportion of patients undergoing catheter ablation and control patients (with normal baseline EF) remained free of $\mathrm{AF}$ (78\% vs. $84 \%$ ), with the rate of redo procedures of $50 \%$. An increase of $\mathrm{EF}$ for $>20 \%$ or complete normalization of $\mathrm{EF}(\geq 55 \%)$ was registered in $72 \%$ of the patients. Importantly, EF significantly increased not only among patients with poor rate control (average increase of EF by 23\%), but also among those with seemingly adequate control of ventricular response prior to the procedure (EF increased by 17\%) [115]. Moreover, among the patients with paroxysmal AF and systolic left ventricular dysfunction, the PV isolation procedure was followed by a significant rise of $\mathrm{EF}$ from $41 \%$ to $51 \%$ [116]. These findings confirm that not only prolonged episodes of persistent AF, but also frequent attacks of paroxysmal AF can lead to development of reversible tachy-cardiomyopathy. Recently, in the long term follow up study of 196 patients with $\mathrm{EF}<50 \%$ (77.6\% of patients had persistent $\mathrm{AF}$ ) who were subjected to catheter ablation of $\mathrm{AF}$, the maintenance of sinus rhythm was independently associated with clinical improvement in terms of the reduction in New York Heart 
Association (NYHA) class of symptoms for $\geq 1$ and relative increase in left ventricular EF $\geq 10 \%$ (OR 4.26 [95\% CI: 1.69 to 10.74], $\mathrm{p}=0.002$ ) [117].

Quality of life. Patients with AF, similar to other cardiovascular patients, have considerably reduced QoL in comparison with general population [3]. Using a standard questionnaire before and after procedure (such as The Short Form (SF-36) Health Survey and Symptom Checklist), it was found that the QoL already improved at 3 months after ablation, and the improvement was sustained in the following 2 years, until the end of the research [118]. Several clinical parameters were identified to be the independent predictors of limited improvement of QoL score after catheter ablation of AF, including obesity, continuation of oral anticoagulant therapy after the procedure and good QoL score prior to the procedure. It could mean that in the presence of significant comorbidities, which limit functional capacity (such as obesity), or when chronic oral anticoagulation therapy is recommended (such as in patients at high risk of thromboembolic events), favourable effects of ablation with respect to symptoms can be mitigated. Thus, more pronounced symptomatic benefit of the procedure could be expected among highly symptomatic patients with "true" lone AF.

Among patients with paroxysmal AF refractory to $\geq 1 \mathrm{AAD}$, the $\mathrm{QoL}$ and symptomatic status were much more improved in those treated by catheter ablation of $\mathrm{AF}$, compared to the patients who continued with AAD therapy [118-120]. In addition, the improvement of QoL scores among patients with persistent AF was greater after catheter ablation than after cardioversion only [92]. The improvement of QoL after ablation comprised all segments valuated by SF-36 questionnaire, including physical functioning, social functioning and mental health, and it reached the general population norms [3, 119]. Furthermore, change of QoL was directly related to the recurrence of arrhythmia after $\mathrm{AF}$ ablation. However, although there was a trend toward greater improvement of QoL after the procedure among patients whose AF was completely eliminated by ablation, significant improvement of life quality was also noted among patients with good pharmacological control of AF after ablation and even among those with arrhythmia recurrences $[118,119]$. This can be explained by the reduction of $\mathrm{AF}$ burden following the procedure, i.e. a transition towards less frequent and more asymptomatic episodes of arrhythmia due to destruction of local autonomic nerve fibers and increased efficiency of AADs after ablation as a result of partially damaged myocardial PV-atrial connections [45, 85]. Thus, catheter ablation provides an opportunity for very efficient symptomatic treatment of patients with $\mathrm{AF}$, which is one of the primary aims of AF therapy [1].

\section{COMPLICATIONS OF AF ABLATION}

Nowadays, catheter ablation of AF represents the most commonly performed interventional procedure in modern electrophysiological laboratories. In the last few years, number of AF ablation procedures increased, and procedure is carried out worldwide [3]. Leading experts described the distinctive strategic approaches, the technology they used and the experience gained so far [120]. Catheter ablation of AF is one of the most complex interventional procedures and its certain segments are associated with higher incidence of complications as compared to the conventional procedures of catheter ablation [120-123]. Complications of AF ablation depend 
on specificity of the energy source used for the procedure, the procedure itself, characteristics of used device and the need for increasing the procedure efficiency [121]. Since there is no firm evidence that AF ablation affects the life expectancy, the primary goal of treatment is the improvement of symptomatic status and QoL. Therefore, it is necessary to discuss with each patient all the risks and benefits of this kind of treatment before the procedure.

Updated worldwide survey on catheter ablation of AF included 16.309 patients with a total of 20.825 procedures performed [123]. Compared to previous report, procedure efficiency and proportion of patients who were free of symptomatic AF without AAD therapy increased significantly in the last 5 years (52\% vs. $70 \%$, $\mathrm{p}<0.0001)$, even though the major complication rate was not notably reduced $(6 \%$ vs. $4.5 \%, \mathrm{p}=0.691)[122,123]$. However, the analysis, which encompassed 192 studies with 83.236 patients, showed a significant decrease of the AF ablation periprocedural complication rate during the period from 2007-2012, compared to the period from 2000 to 2006 (2.6\% vs. 4.0\%, p=0.003) [124]. On the other hand, in the series of 500 consecutive PV-antral isolation procedures, performed in relatively younger patients (average age 54) with low prevalence of structural heart disease and a low $\mathrm{CHADS}_{2}$ score (the score ranged 0-1 in 92\% of patients), an extremely low major complication rate of only $0.8 \%$ was reported [125]. It is very important to keep in mind that the complications of AF ablation do not have to be acute (i.e., do not have to occur during or immediately after the procedure), but also can be delayed, emerging in the upcoming weeks or months following the intervention [3, 120, 122, 123].

\section{Predictors of procedural complication}

The identification of potential predictors of AF ablation procedure complications has important implications and could affect the choice of ablation strategy and technology for a given patient, as well as the selection of patients for the ablation. Several potential predictors of periprocedural complication have been identified.

Age. Although the smaller studies have shown comparable efficacy of AF ablation in both younger and older patients, a conservative approach is generally preferred for older patients, mostly because of the fear from thromboembolic and vascular complications [3]. Controversial data about influence of older age on the periprocedural complications were published. For example, one study showed no significant difference between major complication rates of the AF ablation in three different age groups of patients, namely <65 years, 65-74 years and $\geq 75$ years $(1.6 \%$ vs. $1.7 \%$ vs. $2.9 \%, p=n s)$ [126]. On the contrary, the other two studies demonstrated strong association between the occurrence of complication and older age of $>70$ and $\geq 75$ years $[127,128]$. These findings were recently confirmed by another group of authors who identified age as one of the independent predictors of severe non-fatal procedural complications and death (OR 1.04 [95\% CI: 1.01 to 1.07]; $\mathrm{p}=0.0155$ ) [129].

Female gender. There is consistency of the data from several studies on the increased procedural risk in women [127, 130-132]. An analysis of 517 AF ablation procedures showed that female gender was an independent predictor of major complications (OR 3.0 [95\% CI: 1.3 to 7.2]; p=0.014), while in another study female gender was independently associated with the occurrence of vascular complications (OR 4.4 [95\% CI: 1.72 to 7.75$] ; \mathrm{p}=0.01)[127,130]$. Common femoral artery is much shorter in women compared to men $(38 \mathrm{~mm}$ 
vs. $46 \mathrm{~mm}$ ), which could complicate adequate access to the femoral vein during vascular puncture and increases the risk of forming the pseudoaneurysm and/or arteriovenous fistula [130].

Body weight. During the AF ablation-related risk evaluation, the anthropometric indices of patients must be taken into consideration. An analysis of the $512 \mathrm{AF}$ ablation procedures identified remarkably higher major complication rate among morbid obese patients (body mass index [BMI] $>40 \mathrm{~kg} / \mathrm{m} 2$ ) compared to patients with lower BMI (14.3\% vs. 6.2\%, p=0.046) [132]. For every unit of BMI increment, the probability of complications (mostly vascular) increased by 5\% in the entire group, and more than twice (OR 2.23 [95\% CI: 1.09 to 4.56]; $\mathrm{p}=0.03$ ) among women. However, the other group of authors identified lower body weight as the only independent predictor of complications, with a $0.8 \%$ increased risk for every $10 \mathrm{~kg}$ of body weight reduction, most likely due to a tendency of the underweight patients to be overdosed with anticoagulant drugs during the procedure. The distribution of complication rate among patients $\leq 80 \mathrm{~kg}, 81-90 \mathrm{~kg}, 91-100 \mathrm{~kg}$ and $>100 \mathrm{~kg}$ was $4.8 \%, 3.5 \%, 2.5 \%$ and $2.0 \%$, respectively [133].

Structural heart disease. The presence of structural heart disease represents a risk factor for periprocedural complications of AF ablation. In one study, the history of coronary disease before procedure was identified as an independent predictor of hemorrhagic complications (OR 5.6 [95\% CI: 1.6 to 20.1]; p<0.008) [134]. In another series of 1000 consecutive RF catheter AF ablation procedures, a significant association between congestive HF and periprocedural complications was found (HR 5.2 (95\% CI: 2.0 to 13.4); p=0.001) [128]. According to data from the German multicenter registry which included 6211 patients, the rate of all complications was significantly higher among patients with hypertensive heart disease than among those without structural heart disease $(7.28 \%$ vs. $6.01 \%, \mathrm{p}<0.01)$, with special regard to the periprocedural stroke rate, which was 6.8 times higher among patients with hypertensive heart disease $(0.95 \%$ vs. $0.14 \%, \mathrm{p}<0.001)$. Furthermore, the presence of hypertensive heart disease was an independent predictor of death and severe non-fatal procedural complications (OR 1.97 [95\% CI: 1.02 to 3.83]; p=0.0442) [129].

The type of ablation procedure. It is well known that the recurrence of AF after initial AF ablation is common. Among patients treated with catheter ablation of AF, 10-25\% were subjected to the repeated procedure [120]. In one study, history of previous RF ablation of AF was associated with increased probability of cardiac tamponade at the redo procedure (OR 3.32 [95\% CI: 0.95 to 11.61]; p<0.05), which could be related to scarring and thinning of the LA wall after the first RF ablation [130].

Some studies indicated that the additional ablation of complex AF substrate either with linear ablation or CFAE ablation increases procedure risk [50, 53, 133]. The long procedure time, prolonged catheter manipulation in the LA, a higher energy output and ablation within the coronary sinus in order to achieve transmural lesion, may all increase the risk of perforation and embolism [135]. Interestingly, a systematic literature review (192 studies with 83.236 patients) did not find any significant relation of procedure duration, ablation time and ablation strategy with the occurrence of acute complications [124].

The selection of ablation technology may also affect the occurrence and nature of specific complications. Data from the German registry included 3.775 patients with paroxysmal AF who underwent the PV isolation procedure [136]. A direct comparison of cryoballoon ablation and RF ablation indicated the identical overall complication rate $(4.6 \%$ vs. $4.6 \%)$. The phrenic nerve palsy was significantly more frequent with cryoballoon as compared to RF ablation $(2.1 \%$ vs. $0.0 \%, \mathrm{p}<0.001)$, but the prevalence of other complications was considerably higher with RF current $(4.6 \%$ vs. $2.7 \%, \mathrm{p}<0.05)$. 
Experience of the operator and centre. AF ablation is very demanding and complex procedure and operator's experience in many ways influences the occurrence, recognition and treatment of complications. Learning curve of the catheter ablation procedure was emphasized by many authors. For example, in a series of the first 100 consecutive AF procedures complication rate was $9.0 \%$ and in the following 541 procedures it was twice lower (4.3\%) [127]. Decennial results from the United States registry were recently presented, showing that the intrahospital complication probability regarding AF ablation was notably lower among the operators who perform 25-50 procedures per year (OR 0.51 [0.33 to 0.80]; $\mathrm{p}<0.004)$ and $>50$ procedures per year (OR 0.38 [0.21 to 0.69$] ; \mathrm{p}<0.002)$ compared to less experienced operators ( $<25$ procedures per year) [137].

\section{Specific complications of catheter-ablation of AF}

(Specific procedural complications are presented in details in table 3)

Fatal outcome. Fatal outcome is a rare complication of catheter ablation of AF with incidence of 1:1000, which is similar to the fatality incidence with catheter ablation of supraventricular tachycardias [120, 123]. A multicenter analysis, which included 32.569 patients who underwent $\mathrm{AF}$ ablation, showed that the most common causes of death were cardiac tamponade (25\%), stroke (16\%) and atrioesophageal fistula (16\%) [138]. However, although cardiac tamponade was a rather frequent periprocedural complication (1\%), it had fatal outcome in merely $2.2 \%$ of cases. On the other hand, atrioesophageal fistula was a rare complication $(0.02 \%)$, but most commonly with fatal outcome (71.4\%). The incidence of intraprocedural stroke was $0.2 \%$, with a moderate rate of fatal outcome (5.1\%). It is controversial whether to run the AF ablation procedure without appropriate back up from the cardiac surgery. Namely, an urgent surgical approach was necessary in $13.3 \%$ of patients with cardiac tamponade after an unsuccessful percutaneous pericardiocentesis [139]. It is particularly important to recognize that 25 of 32 fatal outcomes occurred within 30 days of the procedure, of which 12 were intraprocedural (five of them due to cardiac tamponade, two due to stroke) and 13 occurred in the first hours or days after the procedure (five of them due to atrioesophageal fistula, two due to anoxic encephalopathy and two due to massive pneumonia). Majority of patients (71\%) with late fatal outcome at $>30$ days after the procedure experienced some of the intraprocedural acute complications [138]. These data underline the necessity of a careful follow-up of patients during the first weeks after the procedure, especially of those who suffered any of the acute periprocedural complications.

Cardiac tamponade. Cardiac tamponade is the most common life-threatening complication of catheter ablation of AF, with incidence of $1 \%$ to $6 \%$ [120, 123, 124, 125, 133, 125]. Cardiac tamponade may occur due to an inaccurate transseptal puncture, mechanical perforation with catheter or excessive local RF ablation with tissue overheating and steam-popping in the presence of anticoagulation [3, 123]. Rapid accumulation of blood in pericardial sac leads to myocardium compression, sudden hypotension, lack of movement of cardiac silhouette at the fluoroscopy and circulatory shock, demanding an urgent echocardiographic confirmation of the diagnosis and intervention. By direct visualization of the fossa ovalis, using transesophageal or intracardiac echocardiography, the risk of inadvertent perforation of adjacent cardiac structures during the transseptal puncture could be minimized, especially in case of a redo procedure, resistant septum and/or altered anatomical relationships of the relevant structures [30]. Gentle catheter manipulation in the LA and careful energy titration 
using irrigated-tip catheters could reduce the complication rate. In one study, $80 \%$ of myocardial perforations resulting in cardiac tamponade occurred during endocardial linear RF ablation of mitral isthmus and in $80 \%$ of cases popping phenomenon with impedance increase preceded the tamponade, while mechanical perforation of the LA was responsible for the remaining $20 \%$ of cardiac tamponade cases [135]. Energy reduction to $\leq 42 \mathrm{~W}$ significantly reduced the cardiac tamponade rate from $2.9 \%$ to $1.0 \%(\mathrm{p}=0.047)$. The use of intracardiac echocardiography (ICE) during ablation provides an opportunity to titrate local application of RF and prevent popping phenomenon [140]. Besides that, ICE enables early detection of fluid accumulation in pericardial sac (behind posterior and lateral wall of the LA), before hemodynamic deterioration [139]. Due to local thinning, several anatomical regions such as the LA appendage, vestibular component surrounding mitral valve, the LA posterior wall and roof, and the coronary sinus are considered as the predilection sites for mechanical perforation, necessitating a careful catheter manipulation [141]. The new technology development enables better control of contact-force between the catheter tip and the endocardium, which could prevent complications [65, 66]. The emergency percutaneous pericardiocentesis followed by anticoagulation reversal is a life-saving procedure and could be performed with subxyphoid, apical or parasternal approach, but in $13 \%$ of patients it could lead to new complications in the form of pneumothorax, hemothorax and liver injury, while 53\% of patients require treatment because of acute inflammatory pericarditis after the hemopericardium evacuation, which could be followed by recurrent AF [139]. Some authors proposed an alternative transcardiac approach to pericardial space with ongoing autotransfusion of evacuated blood in order to stabilize the patient before surgery [142]. However, the long-term prognosis after successful acute treatment of cardiac tamponade is very good and after complete rehabilitation, ablation procedure could be repeated [120, 135, 142]. Delayed cardiac tamponade, which occurs after an hour or more from the AF ablation (up to 50 days after the procedure) draws special attention. Its incidence is $0.2 \%$ and mechanism is not fully explained. However, it is speculated that this type of pericarditis is mediated by inflammation due to transmural ablation. Majority of such patients present with gradually progressive symptoms (such as agitation, tachycardia, oliguria and others), whilst $13 \%$ of patients experience sudden hypotension and shock [120].

Thromboembolic complications. Preprocedural thrombosis. Transesophageal echocardiography (TEE) performed prior to catheter ablation of $\mathrm{AF}$ (mean age of patients was 57 years, $69 \%$ with paroxysmal $\mathrm{AF}$ ) demonstrated the prevalence of LA appendage thrombus in $1 \%$ of patients, despite adequate anticoagulation with warfarin during $\geq 1$ month before the procedure [143]. The prevalence of thrombus in LA was significantly higher among patients with persistent $\mathrm{AF}$ in comparison to those with paroxysmal $\mathrm{AF}$ (3\% vs. $0.2 \%$ ). In addition, high thromboembolic risk (as measured by a $\mathrm{CHADS}_{2}$ score of $>2$ or a $\mathrm{CHA}_{2} \mathrm{DS}_{2}-\mathrm{VASc}$ score of $>2$ ) was more frequently identified among patients with LA thrombus, than in those without LA (86\% vs. $18 \%$ for $\mathrm{CHADS}_{2}>2$ and $100 \%$ vs. $33 \%$ for $\mathrm{CHA}_{2} \mathrm{DS}_{2}-\mathrm{VASc}>2$, respectively) [143]. The finding of both scores $<2$ had almost maximal negative predictive value for the presence of thrombus in the LA appendage $(99.8 \%$ for the $\mathrm{CHADS}_{2}$ and $100 \%$ for the $\mathrm{CHA}_{2} \mathrm{DS}_{2}$-VASc score). In concordance with these results, in another study, TEE prior to ablation revealed LA thrombus in $1.9 \%$ of patients despite the 4-week preparation by oral anticoagulants [144]. Moreover, patients with the finding of thrombus had significantly larger LA dimension (51 $\pm 6 \mathrm{~mm}$ vs. $44 \pm 8 \mathrm{~mm}, \mathrm{p}=0.006$ ). The strongest predictors of the LA thrombus before the procedure were hypertension (OR 
Table 3. Specific complications of catheter ablation of atrial fibrillation [3, 120, 123-202].

\begin{tabular}{|c|c|c|c|c|c|}
\hline Complication & Incidence & Time to complication & Risk factors & Diagnosis & Treatment \\
\hline Cardiac tamponade & $\begin{array}{l}\text { acute: } 1-6 \% \\
\text { delayed: } 0.2 \%\end{array}$ & $\begin{array}{l}\text { acute: at the } \\
\text { procedure } \\
\text { delayed: up to } 50 \text { days }\end{array}$ & $\begin{array}{l}\text { - mechanical perforation } \\
\text { - excessive ablation } \\
\text { - linear ablation (mitral isthmus) }\end{array}$ & $\begin{array}{l}\text { - fluoroscopy - cardiac } \\
\text { silhouette } \\
\text { - pressure monitoring } \\
\text { - echo (TTE; TEE; ICE) }\end{array}$ & $\begin{array}{l}\text { - pericardiocentesis } \\
\text { - surgical repair }\end{array}$ \\
\hline $\begin{array}{l}\text { Systemic } \\
\text { thromboembolism } \\
\text { (CVI/TIA) }\end{array}$ & $\begin{array}{l}\text { manifest: } 0.94 \% \\
\text { silent: } 11-38 \%\end{array}$ & $\begin{array}{l}\text { acute: at the } \\
\text { procedure } \\
\text { delayed: up to } 2 \\
\text { weeks }\end{array}$ & $\begin{array}{l}\text { - low anticoagulation } \\
\text { - persistent AF, cardioversion } \\
\text { - PVAC } \\
\text { - enlarged LA, echo contrast } \\
\end{array}$ & $\begin{array}{l}\text { - neurologic examination } \\
\text { - CT/MRI }\end{array}$ & $\begin{array}{l}\text { - conservative } \\
\text { - thrombolysis } \\
\text { - intervention }\end{array}$ \\
\hline Air embolism & NA & at the procedure & $\begin{array}{l}\text { - transseptal puncture } \\
\text { - long sheaths in LA } \\
\text { - rapid removal of a catheter } \\
\text { - long apnea episodes }\end{array}$ & $\begin{array}{l}\text { - neurologic examination } \\
\text { - CT/MRI }\end{array}$ & $\begin{array}{l}\text { - supportive therapy } \\
\text { - vasopressor drugs } \\
\text { - oxygen treatment } \\
\text { - aspiration }\end{array}$ \\
\hline Pulmonary vein stenosis & $\begin{array}{l}\text { symptomatic: } 0.3 \% \\
\text { asymptomatic: } 0.5-2 \%\end{array}$ & $\begin{array}{l}\text { mostly }<3 \text { months } \\
\text { rare }>3 \text { months }\end{array}$ & $\begin{array}{l}\text { - ostial, distal PV ablation } \\
\text { - small PV diameter } \\
\text { - small size cryoballoon, small PVAC }\end{array}$ & $\begin{array}{l}\text { - CT/MRI } \\
\text { - lung perfusion scan } \\
\text { - Doppler echo }\end{array}$ & $\begin{array}{l}\text { - angioplasty } \\
\text { - stenting } \\
\text { - } \text { surgery, lobectomy }\end{array}$ \\
\hline Phrenic nerve injury & $0-14 \%$ & at the procedure & $\begin{array}{l}\text { - SVC isolation } \\
\text { - cryoballoon RSPV isolation } \\
\text { - small size cryoballoon, small size PVAC } \\
\end{array}$ & $\begin{array}{l}\text { - high output pacing } \\
\text { - diaphragm movement at } \\
\text { fluoroscopy } \\
\end{array}$ & $\begin{array}{l}\text { - supportive therapy } \\
\text { - spontaneous recovery }\end{array}$ \\
\hline Atrioesophageal fistula & 0.04 & $2-6$ weeks & $\begin{array}{l}\text { - high output RF ablation } \\
\text { - LA posterior wall ablation } \\
\text { - enlarged LA, esophag. reflux }\end{array}$ & $\begin{array}{l}\text { - CT/MRI } \\
\text { - capsule endoscopy }\end{array}$ & $\begin{array}{l}\text { - surgical } \\
\text { - esophageal stenting }\end{array}$ \\
\hline $\begin{array}{l}\text { Esophageal \& } \\
\text { vagal nerves injury }\end{array}$ & $\begin{array}{l}\text { esophageal ulcer: } 17 \% \\
\text { vagal nerve: } 0.3 \%\end{array}$ & after $24-72 \mathrm{~h}$ & the same as for atrioesophageal fistula & $\begin{array}{l}\text { - endoscopy } \\
\text { - fluoroscopy of upper GIT }\end{array}$ & $\begin{array}{l}\text { - PPI } \\
\text { - spontan.recovery } \\
\text { - surgical } \\
\end{array}$ \\
\hline $\begin{array}{l}\text { Vascular complications } \\
\text { at access site }\end{array}$ & $0.5-13 \%$ & at the procedure & $\begin{array}{l}\text { - older patients, female patients } \\
\text { - obesity, diabetes mellitus } \\
\text { - repeated procedures }\end{array}$ & - vascular ultrasonography & $\begin{array}{l}\text { - compression } \\
\text { - intervention } \\
\text { - surgery } \\
\end{array}$ \\
\hline Coronary artery injury & $\begin{array}{l}\text { nonsignificant: } 0-28 \% \\
\text { significant: case rep. }\end{array}$ & at the procedure & $\begin{array}{l}\text { - previous lesions } \\
\text { - inferior mitral isthmus ablation } \\
\text { - ablation inside CS }\end{array}$ & - coronary angiography & - PCI with stenting \\
\hline $\begin{array}{l}\text { Circular catheter } \\
\text { entrapment }\end{array}$ & $0.01 \%$ & at the procedure & $\begin{array}{l}\text { - vigorous manipulation of catheter in LA } \\
\text { and LIPV }\end{array}$ & $\begin{array}{l}\text { - fluoroscopy } \\
\text { - echocardiography }\end{array}$ & $\begin{array}{l}\text { - gentle catheter manipulation, } \\
\text { advancing the sheath } \\
\text { - surgery }\end{array}$ \\
\hline $\begin{array}{l}\text { Atrial tachycardia / } \\
\text { flutter after ablation }\end{array}$ & $5-44 \%$ & $\begin{array}{l}\text { early: }<3 \text { months } \\
\text { delayed: }>3 \text { months }\end{array}$ & $\begin{array}{l}\text { - LA inflammation } \\
\text { - ablation of persistent AF } \\
\text { - incompl. lines, CFAE ablation } \\
\end{array}$ & $\begin{array}{l}\text { - ECG } \\
\text { - Holter monitoring } \\
\text { - loop recorder } \\
\end{array}$ & $\begin{array}{l}\text { - AAD } \\
\text { - anti-inflammatory drugs } \\
\text { - new RF ablation } \\
\end{array}$ \\
\hline
\end{tabular}




\begin{tabular}{|c|c|c|c|c|c|}
\hline Radiation injury & $\begin{array}{l}\text { skin injury: } 2 \text { cases } \\
\text { malignances: } 0.1 \%\end{array}$ & $\begin{array}{c}\text { 3-8 months } \\
\text { late complication }\end{array}$ & $\begin{array}{l}\text { - long radiation exposition } \\
\text { - obesity }\end{array}$ & $\begin{array}{l}\text { - dermatological examination } \\
\text { - skin biopsy }\end{array}$ & $\begin{array}{l}\text { - topical and oral steroids } \\
\text { - antihistamines } \\
\text { - antibiotics }\end{array}$ \\
\hline Infective endocarditis & $0.2 \%$ & few days -4 weeks & $\begin{array}{l}\text { - artificial valves } \\
\text { - congenital heart disease }\end{array}$ & $\begin{array}{l}\text { - blood tests, blood culture } \\
\text { - echocardiography }\end{array}$ & $\begin{array}{l}\text { - antibiotics } \\
\text { - surgery }\end{array}$ \\
\hline
\end{tabular}

Abbreviations:

TTE=transthoracic echocardiography; TEE=transesophageal echocardiography; CVI=cerebrovascular insult; TIA=transitory ischemic attack; PVAC=pulmonary vein ablation catheter; $\mathrm{CT}=$ computed tomography; $\mathrm{MRI}=$ magnetic resonance imaging; $\mathrm{SVC}=$ superior vena cava; $\mathrm{RSPV}=$ right superiori pulmonary vein; $\mathrm{AE}=$ atrioesophageal;

$\mathrm{GI}=$ gastrointestinal; $\mathrm{PPI}=$ proton pump inhibitors; $\mathrm{CS}=$ coronary sinus; $\mathrm{PCI}=$ percutaneous coronary intervention; $\mathrm{LIPV}=$ left inferior pulmonary vein;

Other abbreviations as in tables 1 and 2 . 
14.2 [95\% CI: 2.6 to 77.5 ]; $\mathrm{p}=0.002$ ), older age $>75$ years (OR 8.1 [95\% CI: 1.5 to 44.9 ]; $\mathrm{p}=0.017$ ) and cardiomyopathy (OR 10.5 [95\% CI: 2.6 to 77.5$] ; \mathrm{p}=0.002$ ).

Among the patients free from clinical risk factors (such as age $>75$ years, diabetes, hypertension, valvular heart disease, stroke or TIA) thrombus was not found [144].

Intraprocedural (thrombo)embolism. Embolism related to catheter ablation of AF can be mediated by several factors, including tissue detritus during the transseptal puncture, thrombosis of long introducers and catheters in the LA, introduction of air in systemic circulation by exchanging the catheters through the long introducers, mechanical dislodgement of preexisting LA thrombus during the catheter manipulation, cardioversion of persistent AF during the procedure, catheter tip charing due to a high RF energy output without adequate local cooling, thermally-induced denaturation of plasma proteins during ablation, administering of protamine at the end of procedure, etc. [3, 120-123].

The incidence of (thrombo)embolism due to catheter ablation of AF ranges from $1 \%$ to $2 \%[26,123]$. Systemic thromboembolism can cause ischemic stroke or acute occlusion of coronary or peripheral artery, which determines specific clinical presentation [145-147]. A massive stroke during AF ablation can be fatal (5.1\%) or can lead to significant neurological dysfunction [138]. According to one study, stroke was most often (60\%) reported during the procedure or within $24 \mathrm{~h}$ after the procedure, about $30 \%$ of cases were registered between $24 \mathrm{~h}$ and $48 \mathrm{~h}$ after the procedure, and additional $10 \%$ of strokes occurred by the end of the first week after the ablation [146]. Among the patients who have suffered the procedural stroke, the level of neurological impairment was severe in $11.5 \%$, moderate in $38.5 \%$ and mild in $34.6 \%$ of patients. During a 38 -month followup after the procedure, $7.7 \%$ of these patients died, while the remaining patients have achieved complete neurological recovery [147]. Symptomatic procedural thromboembolic cerebrovascular complications can be treated by emergency percutaneous intervention with mechanical recanalization of culprit artery or by administration of thrombolytic therapy $[3,120]$. However, it seems that symptomatic stroke represents only "the top of the ice berg", because cerebral MRI scanning, performed just before and after catheter ablation of AF, detected a disturbing rate of asymptomatic brain embolism of 1.7-38\% [148, 149]. Fortunately, follow-up MRI obtained several weeks later demonstrated complete regression of these brain lesions. In fact, only 1-3\% of these lesions persisted on repeated MRI examination, and those were mainly the lesions with larger diameter at baseline (>1 cm) [149]. At this moment, true potential of such asymptomatic lesions for late deterioration of cognitive function and development of dementia is not clear. However, electrophysiologists are alarmed to identify and conduct adequate prevention measures in order to reduce occurrence of this complication.

Occurrence of procedural thromboembolic complications depends on the clinical characteristics of patients, the use of ablative technology, chosen ablative strategy (i.e. set of lesions) and anticoagulation regimen during the procedure [149]. Several authors emphasized the predictive significance of older age, presence of hypertensive heart disease, a high $\mathrm{CHADS}_{2}$ score of $\geq 2$ (OR 7.1 [95\% CI: 1.3 to 38.0]; $\mathrm{p}=0.02$ ) and history of cerebrovascular insult (OR 9.5 [95\% CI: 2.2 to 40.9]; p<0.01) for high risk of occurrence of procedural thromboembolic cerebrovascular complications $[3,129,146,150]$. In another study, the presence of a $\mathrm{CHADS}_{2}$ score of $\geq 2$ carried 9 times higher risk of procedural thromboembolism, in comparison with $\mathrm{CHADS}_{2}$ score $\leq 1$ (4.7\% vs. $0.5 \%)$ [146]. Important role in the occurrence of procedural thromboembolism belongs to certain technical aspects of the procedure. Thus, for example, the long sheath perfusion rate (low flow vs. high flow) was one of the risk factors for the occurrence of cerebrovascular thromboembolism (OR 17.3 [95\% CI: 1.1 to 
260.8]; $\mathrm{p}=0.04$ ) during the LA catheter ablation procedures [120, 151]. Indeed, with increasing the introducer perfusion rate (from $3 \mathrm{~mL} / \mathrm{h}$ to $180 \mathrm{~mL} / \mathrm{h}$ ) the incidence of cerebral thromboembolism was reduced from $11.9 \%$ to $0 \%$ [151]. Furthermore, several recent studies demonstrated differences in embolic risk, depending on the ablative technology and strategy. The risk for the occurrence of new subclinical cerebrovascular embolization was similar with the use of irrigated-tip RF catheters $(6.8 \%-8.3 \%)$ and cryoballoons $(4.3 \%-8.9 \%)$, but it was significantly higher with ablation by phased multielectrode RF catheter (PV ablation catheter, so called PVAC) [152-154]. In addition, ablation strategy has a direct impact on the prevalence of new asymptomatic cerebral (thrombo)embolizations after the procedure: 5.4\% with isolation of PVs only, $16.0 \%$ with additional linear ablation (PV isolation + lines) and 31.5\% with further CFAE ablation (PV isolation + lines + CFAE). Moreover, CFAE ablation was independently related to the occurrence of asymptomatic cerebral lesions on early postprocedural MRI (OR 6.7 [95\% CI: 1.7 to 25.6]; $\mathrm{p}=0.006$ ) [155].

Thromboembolism after procedure. Thromboembolic events may arise within the weeks and months after the procedure, due to a number of various factors, such as endothelial disruption induced by local ablation, loss of the LA transport after extensive ablation, artificial isolation of the LA appendage, LA stunning following cardioversion, recurrence of AF after the procedure and intrinsic thromboembolic risk of the patient [1, 3, 120].

The previous studies have shown potential value of the $\mathrm{CHA}_{2} \mathrm{DS}_{2}$-VASc scoring system in evaluation of thromboembolic risk after AF ablation. Over the long term follow-up period of 38 months after AF ablation, $4.8 \%$ of a total of 565 study patients have suffered some adverse event, including thromboembolism [156]. Adverse events were more common among patients with $\mathrm{AF}$ recurrence than among those who were free of $\mathrm{AF}$ (9.6\% vs. $2.8 \%, \mathrm{p}=0.001$ ). The only independent predictors of stroke or TIA were the $\mathrm{CHADS}_{2}$ score (HR 1.9 [95\% CI: 1.4 to 2.6] for each unit increment; $\mathrm{p}<0.001$ ) and the $\mathrm{CHA}_{2} \mathrm{DS}_{2}$-VASc score (HR 1.7 [95\% CI: 1.3 to 2.2] for each unit increment; $p<0.001$ ). It is critically important that even $2.4 \%$ of "low risk" patients with $\mathrm{CHADS}_{2}$ score 0 to 1 were affected by some of adverse events. Furthermore, among patients with low CHADS 2 score $\leq 1$, the risk of adverse events gradually increased, in parallel with the value of $\mathrm{CHA}_{2} \mathrm{DS}_{2}$-VASc score ( $0.6 \%$ for score $0,1.6 \%$ for score $1,6.2 \%$ for score 2 and $11.8 \%$ for score 3 ) [156]. Therefore, it seems that the $\mathrm{CHA}_{2} \mathrm{DS}_{2}$-VASc scoring system is more sensitive (than $\mathrm{CHADS}_{2}$ ) for assessment of thromboembolic risk after catheter ablation of AF. Recently, another study confirmed these results [157]. During the 18-month follow-up after the procedure the prevalence of thromboembolic events was 0.72\%. Among patients with low $\mathrm{CHADS}_{2}$ score (0-1), the use of $\mathrm{CHA}_{2} \mathrm{DS}_{2}$-VASc score provided additional differentiation of thromboembolic risk. The risk was only $0.13 \%$ with a $\mathrm{CHA}_{2} \mathrm{DS}_{2}$-VASc score of $0-1$ and $0.71 \%$ with a $\mathrm{CHA}_{2} \mathrm{DS}_{2}$-VASc score of $>2$. In addition, it seems that the $\mathrm{CHA}_{2} \mathrm{DS}_{2}-\mathrm{VASc}$ score has the best predictive value in patients with $\mathrm{AF}$ recurrence after catheter ablation [157].

Periprocedural anticoagulation strategies. The presence of thrombus in the LA appendage is a contraindication for catheter ablation of $\mathrm{AF}[3,120]$. Thus, it is necessary to take appropriate measures for prevention of thrombus formation and for its early detection. The patients should be anticoagulated systemically with a vitamin K antagonist at the therapeutic level (International Normalized Ratio [INR] between 2 and 3) or with a new oral anticoagulant drug (direct thrombin or Factor Xa inhibitor) for at least 3-4 weeks prior to the procedure $[1,3,120]$. TEE before ablation procedure probably is not necessary in all patients, but it could be very important for selected high risk patients, such as those with persistent $\mathrm{AF}$, patients having $\mathrm{AF}$ on the day of the procedure, especially if episode of AF lasted $>48 \mathrm{~h}$, as well as patients with high a $\mathrm{CHADS}_{2}$ score of $\geq 2$, a 
subtherapeutic INR of $<2$ during the previous weeks and patients with considerably dilated LA [158]. Only with younger patients with low $\mathrm{CHADS}_{2}$ score $\leq 1$, normal LA dimension and paroxysmal lone AF, presenting in sinus rhythm at ablation procedure, simplified alternative therapy only with aspirin, can be considered [159].

Generally, there are two periprocedural anticoagulation strategies [3, 120]. According to the classical strategy, warfarin is interrupted 3-4 days before the procedure and during those days it should be overlapped with low-molecular-weight heparin (LMWH: enoxaparin or dalteparin). After procedure, warfarin is reinitiated (with LMWH bridging until the therapeutic INR of $>2$ is reached) [120, 158]. Another strategy is increasingly applied and it consists of continuous warfarin therapy throughout the whole periprocedural period, without interruption. During the procedure, INR is maintained in lower therapeutic range of 2 to 2.5, and application of subcutaneous LMWH in periprocedural period is not necessary $[158,160]$. The main concern with uninterrupted warfarin strategy is related to possible procedural bleeding.

A reversion of anticoagulant effects of unfractionated heparin usually is achieved quickly with intravenous administration of protamine [120]. However, in case of bleeding under therapeutic INR, availability of fresh frozen plasma, vitamin K or recombinant Factor VIIa during the procedure is mandatory and complete neutralization of anticoagulant effect is much slower $[3,158,160]$. In recent years several studies analyzed effects of anticoagulant strategy in relation to thromboembolic and bleeding complications. A meta-analysis, which included 9 studies and total of 27402 patients who underwent AF ablation, showed that continuous warfarin strategy, in comparison with "overlapping” strategy, significantly reduces the risk of thromboembolic complications (OR 0.10 [95\% CI: 0.05 to 0.23]; p<0.001) and minor bleeding (OR 0.38 [95\% CI: 0.21 to 0.71 ]; $\mathrm{p}=0.002$ ) during the periprocedural period [160]. On the other hand, the risk of major bleeding, including cardiac tamponade, was not significantly increased. It was pointed out that safe adoption of this strategy obligates to ICE monitoring during the procedure, due to tendency towards increase of the risk of major bleeding if ICE was not used (OR 2.69 [95\% CI: 0.87 to 8.33]; p=0.086) [160]. A recent retrospective research confirmed these findings [161]. Comparing these two anticoagulation strategies in a total of 3280 patients, there was a significant reduction in the rate of ischemic stroke/TIA among patients on continuous warfarin therapy $(0.67 \%$ vs. $0.15 \%$, $\mathrm{p}=0.02$ ), while the incidence of severe hemorrhagic complications (mostly cardiac tamponade) was similar (1.3\% vs. $1.1 \%, \mathrm{p}=0.80)$.

In the last few years, novel oral anticoagulation drugs are being increasingly used in periprocedural anticoagulation [162-164]. Several recent studies investigated the efficacy and safety of periprocedural anticoagulation with dabigatran for catheter ablation of AF [162]. In a meta-analysis that included 11 studies, continuous warfarin therapy (therapeutic INR 2-3) was compared with dabigatran (at a daily dose of 2x150mg) for periprocedural anticoagulation in $\mathrm{AF}$ ablation procedure [163]. In most of the studies, dabigatran was discontinued at the morning of the procedure or 1 to 2 days prior to procedure, while the strategy with uninterrupted dabigatran throughout the entire periprocedural period was accepted in only two studies. A total of 3841 patients were enrolled (mostly with a low $\mathrm{CHADS}_{2}$ score of 1.0-1.1), who were treated by irrigation RF ablation of AF, and dabigatran was as efficient and safe as warfarin [163]. There was no significant difference in the prevalence of thromboembolic complications $(0.6 \%$ vs. $0.1 \%, \mathrm{p}=0.12)$, major bleeding $(1.9 \%$ vs. $1.6 \%$, $\mathrm{p}=0.92)$, cardiac tamponade $(1.4 \%$ vs. $1.1 \%, \mathrm{p}=0.82)$ and minor bleeding $(3.8 \%$ vs. $4.5 \%, \mathrm{p}=0.40)$ between dabigatran and warfarin group, respectively. In addition, a multicenter observational study demonstrated that interrupted anticoagulation periprocedural strategy with rivoraxaban was safe and efficacious compared to 
warfarin for the prevention of bleeding and thromboembolic events in patients who underwent $\mathrm{AF}$ ablation [164]. In this study, the rate of major bleeding complications (1.6\% vs. 1.9\%), minor bleeding complications $(5.0 \%$ vs. $5.9 \%)$ and thromboembolic events $(0.3 \%$ vs. $0.3 \%)$ were similar between patients treated with rivaroxaban and warfarin, respectively.

Throughout the procedure, regardless of the anticoagulation strategy used, intravenous unfractionated heparin is administered, with a loading dose of $100 \mathrm{IU} / \mathrm{kg}$ and then the application of the drug continues as an infusion or as repeated boluses in a dose of approximately $10 \mathrm{IU} / \mathrm{kg}$ per hour, keeping the activated clotting time (ACT) in therapeutic range $[3,120]$. Catheter ablation of $\mathrm{AF}$ under therapeutic INR is simple and requires smaller dose of intravenous heparin during the procedure [165].

The study, which compared three different levels of procedural anticoagulation (250-300 sec, 300-350 sec and 350-400 sec), reported that more aggressive anticoagulation with target ACT $>300 \mathrm{sec}$ is associated with significantly lower prevalence of thromboembolic cerebral events, such as ischemic stroke and TIA [166]. It seems that more intensive anticoagulation during the procedure could be justified in the patients with high thromboembolic risk. For example, maintaining the procedural ACT $>300 \mathrm{sec}$ efficiently prevented thrombus formation in the LA, especially in patients with spontaneous LA echo contrast at the beginning of the procedure [167].

Anticoagulation therapy following procedure. Optimal duration of anticoagulant therapy after the procedure is not completely clarified. In the weeks after the ablation procedure, damaged endothelium represents possible nidus for thrombus formation [120, 158]. Although most of AF recurrences are registered in the first 1-2 years, the attention is drawn to appearance of later arrhythmia relapse [79]. Moreover, AF recurrences after the procedure can be completely asymptomatic [3]. Even after successful elimination of AF by ablation, some patients are still prone to thromboembolism due to the presence of many comorbidities and risk factors, remaining after the procedure [168]. Therefore, systemic anticoagulation is indicated in all patients in the first 26 months post procedure, depending on the ablation extensiveness (PV isolation vs. PV isolation + substrate modification) [3, 120]. Following this period, it is possible to discontinue oral anticoagulant therapy in some, but not all patients. Although some authors have successfully stopped the anticoagulation therapy in over $80 \%$ of the patients during long term follow-up, it is recommended to continue treatment indefinitely in selected patients with high $\mathrm{CHADS}_{2}$ score $\geq 2$ [168]. As already mentioned, several recent studies suggested potential value of $\mathrm{CHA}_{2} \mathrm{DS}_{2}$-VASc score in further stratification of so called "low risk" patients (based on a low $\mathrm{CHADS}_{2}$ score of 0-1) after catheter ablation of AF. Thus, despite low $\mathrm{CHADS}_{2}$ score, in patients with a $\mathrm{CHA}_{2} \mathrm{DS}_{2}-\mathrm{VASc}$ score of $\geq 2$ and/or recurrence of $A F$, long term anticoagulation after the procedure should be considered $[156,157]$.

Pulmonary vein stenosis. PV stenosis is one of the most serious complications of catheter ablation of $\mathrm{AF}$ and could lead to a lifelong reduction of patient's functional capacity [3, 120, 123, 124]. By changing ablation technique, i.e. by relocating ablation site away from PV ostium (to more antral region), incidence of PV stenosis was significantly reduced in the last ten years, from $28 \%$ (in initial series) to current $1.3 \%$, whilst incidence of PV stenosis that needed intervention is $0.3 \%$ [123, 169]. Arbitrarily, severity of PV stenosis was labelled as mild ( $<50 \%$ of diameter), moderate $(50 \%$ to $70 \%)$ and severe or significant $(>70 \%)$ [3]. Based on porcine models it is suggested that PV stenosis appears due to thermal injury of the PV wall, intensive periadventitial inflammation and progressive collagen deposition, which causes lumen narrowing [170]. 
Rather well balanced distribution in stenosis of left superior (32\%), left inferior (26\%) and right superior PV (35\%) was noticed while involvement of right inferior PV occurred less frequently (6\%) [171]. A repeated ablation procedure was responsible for $26 \%$ of all cases of PV stenosis. The onset of symptoms is often delayed (approximately $103 \pm 100$ days after the procedure) and insidious in the form of exertional dyspnoea, cough, haemoptysis, chest pain or bronchitis/pneumonia [170-172]. Clinical presentation depends on number of PVs affected and degree of stenosis. Namely, symptoms occur as consequence of pulmonary congestion and usually begin when stenosis is $>60-70 \%$, especially among patients with involvement of $>1$ PV [170]. Thus, $82 \%$ of patients with substantial stenosis of one PV and $100 \%$ of patients with stenosis of 2,3 or 4 PVs reported the symptoms [172]. Therefore, it is recommended to perform routine screening of patient three months after AF ablation, which enables timely detection and following of initial PV stenosis [120]. Anatomic lesion evaluation is performed with computed tomography (CT) and MRI scanning, whereas determination of the degree of physiological disorder is performed by lung perfusion scan [170]. Prevention of this complication could be accomplished with as accurate as possible identification of PV ostium before ablation by using selective venography, impedance map, local electrograms features, 3D electro-anatomical mapping systems with image integration from CT/MRI scan and ICE [3, 120, 170].

Until recently it was believed that development of PV stenosis was primarily associated with the usage of RF energy. However it is reported that this complication occurs also during cryoablation of AF, especially when smaller balloons are used [173]. Interventional angioplasty with stent implantation probably presents currently the most effective therapy of significant PV stenosis [174, 175]. Long-term rate of restenosis after stenting is lower than after the angioplasty (33\% vs. 78\%) and substantially higher in smaller PV with diameter less than $1 \mathrm{~cm}[3,120,174,175]$. There is no clear standpoint about therapy of asymptomatic PV stenosis because if PV occlusion happens prior to symptoms emerge, therapeutic possibilities may be lost and treatment outcome is unsatisfactory. Thus the procedure should be considered in younger asymptomatic patients without comorbidity, particularly if diameter of involved vein is larger [175]. Surgery is reserved for clinically significant occlusion or stenosis and after the failed percutaneous intervention [3].

Esophageal injury and atrioesophageal fistula. Atrioesophageal fistula is a rare but catastrophic complication of catheter ablation of $\mathrm{AF}$ and its incidence is estimated at 0.04\% [123]. Esophagus is located behind the LA and it is in close anatomic relationship with its posterior wall, and contact area could be even larger in patients with LA dilatation, esophageal diverticulosis and thinner adipose-fibrous layer between the LA and esophagus [176]. Thermal injury of esophageal wall and impairment of small blood vessels cause ischemic necrosis of its mucosa and lead to local inflammation and ulceration formation, which are prerequisites for occurrence of atrioesophageal fistula [176]. One study shows that incidence of esophageal mucosal injury after the catheter ablation of AF was $17 \%$ [177].

It is considered that esophageal hypomotility, gastroesophageal reflux and hyperacidity could play important role in further local lesion evolution [120]. Clinical presentation of atrioesophageal fistula usually begins 2-6 weeks after the procedure with unspecific symptoms in the form of dysphagia, odynophagia, nausea, hemathemesis, melena, febricity, pericardial effusion, sepsis, seizures and stroke, due to cerebral embolization with air or food particles $[178,179]$. Therefore, for prompt diagnosis it is necessary to maintain a high suspicion of this delayed complication in patients that had been subjected to catheter ablation of AF during previous weeks 
[3]. In these circumstances, conventional endoscopy is contraindicated because insufflation of the esophagus during the procedure could lead to massive air embolism with consequent stroke or myocardial infarction [179]. Capsule endoscopy procedure is feasible and safe and the method of choice is contrast enhanced thoracic CT $[176,177]$. Many different procedures aiming to prevent esophageal injury were presented during the last few years. During the procedure, direct and real-time visualization of esophagus enables operator to modify ablation trajectory in the LA and to move away from esophagus. It could be accomplished with simple esophageal opacification by ingestion of barium paste, using of ICE and creating 3D geometrical map of esophagus and LA with integration of CT/MRI scan by means of electroanatomical mapping system [3, 120, 176, 177].

In the first weeks after $\mathrm{AF}$ procedure, proton pump inhibitors are often prescribed prophylactically, hoping to accelerate healing of occult esophageal injury as possible precursor for atrioesophageal fistula [180]. Direct monitoring of intraluminal temperature with thermocouple esophageal probe during procedure provides an opportunity to adjust RF energy at ablation on posterior wall of the LA and reduces incidence of esophageal mucosal lesion from $36 \%$ to $6 \%$ [181]. Limiting the RF energy on the LA posterior wall at $25-30 \mathrm{~W}$ also significantly reduced occurrence of esophageal mucosal lesions [176]. In selected cases, esophagus protection during ablation was achieved with different techniques. Thus in smaller series it is attempted to temporarily relocate esophagus during RF ablation by deflection of the endoscope. In other report, with the percutaneous pericardial approach and by placing a balloon filled with liquid behind posterior wall of the LA it was possible to complete redo PV isolation procedure without esophageal injuries which limited index procedure [176].

Experiments on the porcine model revealed a tendency of RF energy to cause greater structural damage and tearing of elastic fibers of esophageal tissue in comparison with cryoenergy, suggesting that cryoenergy could eliminate the risk of collateral esophageal injury during left atrial ablation [182]. However, few clinical cases of atrioesophageal fistula even after cryoballoon isolation of PVs were recently described [183]. It is necessary to obtain proper diagnosis before appearance of dangerous systemic embolization. Surgical treatment requires cooperation between cardiac surgeon and abdominal surgeon, with correction of atrial and esophageal defect with pericardial patch and pericardial or muscular flap, respectively [3, 120, 176]. Case series of successful nonsurgical treatment with esophageal stenting and subsequent stent removal after fistula resolution was reported [178].

Periesophageal vagal plexus injury is rare complication of AF ablation and could lead to functional esophageal disorder. Vagal nerve fibers, which control peristalsis, pyloric sphincter and gastric antrum mobility, are located along the anterior esophageal wall and make anterior esophageal plexus which is placed adjacent to posterior wall of the LA $[120,176,184]$. The usage of RF energy at the posterior wall of the LA could be complicated by injuring this nerve plexus and causing an acute pyloric spasm, esophageal and gastric hypomotility as well as a slow/delayed gastric emptying [184]. In a series of 3.695 consecutive patients subjected to ablation of AF, vagal nerve injury was diagnosed among 11 patients (0.3\%) [185]. Symptoms typically started within 72 hours from the procedure, usually after taking the first meal after procedure. Those were nausea, vomiting, flatulence, abdominal pain and constipation. Initially, stimulation of peristalsis with erythromycin and metoclopramide was applied. In the next 2-6 weeks, symptom resolution was registered in $72 \%$ of patients, while $28 \%$ of patients suffered from prolonged symptoms (3-12 months). Due to persistent pyloric stenosis in one patient, after two attempts of endoscopic dilatation, laparoscopic surgical correction with gastrojejunal anastomosis along with partial gastric resection was performed [185]. 
Acute occlusion of coronary arteries. Injury of epicardial coronary artery is not expected during the $\mathrm{PV}$ isolation, it could be a sporadic but very serious complication of ablation of AF substrate in the left or right atrium [120]. Circumflex coronary artery and distal coronary sinus are in close anatomical relationship. In one series of patients who underwent inferior mitral isthmus ablation, coronary sinus ablation using irrigated-tip catheters was performed in $71 \%$ of patients in order to obtain transmurality of the lesion [186]. Selective coronary angiography, performed before and after the ablation, demonstrated clinically silent but angiographically significant stenosis of distal segment of circumflex coronary artery in $28 \%$ of patients, which completely disappeared after intracoronary nitroglycerine administration. Distal coronary sinus, prolonged RF application inside the coronary sinus, smaller circumflex artery diameter, and shorter distance between circumflex artery and coronary sinus were identified as the risk factors for coronary artery lesion within this cohort [186]. Furthermore, other authors described cases of circumflex artery acute occlusion with the development of acute myocardial infarction after epicardial ablation of mitral isthmus via coronary sinus in redo procedure [187]. It is considered that artery occlusion was mediated by direct thermal injury of its wall with edema or spasm and/or cumulative injury from previous procedure. In complex AF procedures, ablation of substrate is not limited to the LA [25]. It has been shown that RF ablation of cavo-tricuspid isthmus could be accompanied by temporary but significant reduction of fractional flow reserve (FFR) in $21.2 \%$ of patients, or rarely by acute occlusion of distal segment of right coronary artery with inferior myocardial infarction [188, 189]. A coronary artery injury induced with RF ablation usually is treated by emergency percutaneous coronary procedure with artery recanalization and stenting [3, 187].

Phrenic nerve injury. Phrenic nerve injury occurs due to direct thermal injury of nerve fibers during ablation [190-192]. Importantly, potentially reversible functional disorder occurs prior to irreversible damage of nerve fibers, thus opening the window for early recognition and prevention of this complication [120]. The right phrenic nerve is in close anatomical relationship with anterolateral wall of superior caval vein, then goes down and posteriorly, and passes near the junction between the LA and anterior wall of the right superior PV at a distance of $<2 \mathrm{~mm}$ in $32 \%$ of patients, while the left phrenic nerve passes over the roof of the LA appendage [190].

In clinical practice, the damage of right phrenic nerve is most frequently seen during the right superior $\mathrm{PV}$ isolation by cryoballoon and during the isolation of superior caval vein by $\mathrm{RF}$ ablation $[3,8,136]$. However, there are few reports on paresis of left phrenic nerve during cryoballoon isolation of the left inferior PV [191]. It is well known that cryoballoon isolation of the PVs is associated with the occurrence of this complication, and that the usage of balloon with a diameter smaller than $23 \mathrm{~mm}$ particularly increases complication risk (7.5\%) due to more ostial energy application and distension of terminal part of the vein [190]. Recently, it has been reported that using balloons with a larger diameter $(28 \mathrm{~mm})$ the incidence of phrenic nerve palsy was reduced to $2.2 \%$, but it was still significantly higher than while using RF current [136, 173, 192].

Nearly one-third of patients with phrenic nerve lesion are completely asymptomatic [190]. However, in symptomatic patients clinical presentation may be nonspecific and includes dyspnea, cough, hiccup, pneumonia, atelectasis and pleural effusion with hemidiaphragm elevation at conventional chest radiogram [3]. Unfortunately, at this moment specific treatment does not exist and, therefore, prevention is of primary importance. A high output pacing from the tip of the ablation catheter should be performed before applying RF 
ablations at posterolateral segment of superior caval vein-right atrial junction, to avoid the damage of the right phrenic nerve [8]. During cryoballoon ablation, especially at the right PVs, continuous monitoring of diaphragm movement is essential and in case of decreased hemidiaphragm excursions at fluoroscopy and occurrence of hiccup and cough, further energy application should be immediately stopped [120, 190]. Clinical outcome of this complication is mainly auspicious. Spontaneous and complete recovery was registered in $81 \%$ of patients approximately seven months after the procedure [136, 190].

Vascular complications. Vascular complications of AF ablation occur at the vascular access site and present the most common complications of catheter ablation of AF with an incidence of 1.5\% [123]. They include hematoma, arterial dissection, arteriovenous fistula, pseudoaneurysm and venous thrombosis at the vascular puncture site, mostly in the groins or in the subclavian region. These complications may lead to prolonged hospital stay, need for blood transfusion, or percutaneous vascular or surgical correction [193]. Women, older and obese patients, diabetics and patients subjected to repeated procedures could be particularly prone to occurrence of vascular complications [130].

Aggressive anticoagulation during the catheter ablation of $\mathrm{AF}$, multiple large sheaths and prolonged procedure time make vascular complication rate higher than at the other electrophysiological procedures [3, 123]. Higher vascular complication rate also occurs with inexperienced operators at the start of the electrophysiological training [130]. Occurrence of vascular complications could be minimized with careful vascular access, manual hemostasis and observation of puncture site after the intervention. By changing the regimen of anticoagulation in the early post-procedural period and by the reduction of enoxaparin dose from 1 $\mathrm{mg} / \mathrm{kg}$ twice a day to $0.5 \mathrm{mg} / \mathrm{kg}$ twice a day, the rate of vascular complications was significantly reduced from $5.7 \%$ to $1.6 \%$ [193]. Vascular complications often could be treated conservatively, by reversal of anticoagulation and echo-guided manual compression. However, treatment with artery stenting or vascular surgical reparation of blood vessel defect is sometimes required $[3,120]$.

Atrial tachycardia and flutter following AF ablation procedure. The incidence and mechanism of atrial tachycardia after catheter ablation of AF primarily depend on the ablation technique used in the first procedure and the type of AF before the ablation (paroxysmal vs. persistent) [194]. Atrial tachycardia could develop as a consequence of proarrhythmic effect of ablation due to incomplete circumferential or linear ablation, but also as a transitional atrial tachyarrhythmia from AF to sinus rhythm, resulting from the modification of substrate of AF and "organization" of AF to a regular tachycardia [25, 42]. Besides that, atrial tachycardia after ablation of AF could arise due to proarrhythmic effect of the class I and class III AADs [1]. Ablation limited to the ostial PV isolation is very rarely associated with a post-procedural atrial tachycardia, with an incidence of $2 \%-7.7 \%$ [7, 69, 194]. However, circumferential antral PV isolation, particularly if it is combined with additional modification of AF substrate, whether by the linear LA ablation and/or CFAE ablation, may lead to the occurrence of atrial tachycardia in $7.6 \%-44 \%$ of patients [24, 42, 54, 194-196]. After usage of similar ablative strategy (CFAE + PVI), post-procedural incidence of atrial tachycardia was remarkably higher after the ablation of persistent AF than after the ablation of paroxysmal AF (20.0\% vs. 2.4\%) [197].

Mechanism of atrial tachycardia generally is macro-reentry (42\%-88\%), and the arrhythmia is maintained by a large atrial circuit and conditioned by certain anatomical barriers (the atrioventricular annulus, 
PV ostium) or by scar. Focal atrial tachycardias occur less frequently (12\% to 37\%) and originate from smaller and limited anatomical regions with centrifugal passive activation of remaining parts of the atrium [198, 199]. This type of tachycardia may be driven by different mechanisms, including an abnormal automaticity, trigger activity and micro-reentry (usually confined to an area of $<2-3 \mathrm{~cm}$ ). It is very important to keep in mind that even $70 \%-81 \%$ of patients suffer from multiple atrial tachycardias (1.8-3.4 per patient) and, not infrequently, those atrial tachycardias are very complex and in the form of double-loop reentry [200]. Macro-reentrant atrial tachycardia may occur in form of peri-mitral flutter (39\%-61\%), roof-dependent flutter (21\%), macro-reentrant tachycardia around ipsilateral the PVs (9\%-61\%), typical peritricuspid atrial flutter (10\%-15\%) and scar-related atrial tachycardia [194, 199]. Typically, source of focal atrial tachycardia is located in the PV antrum (mostly near the previous ablation site), in inter-atrial septum, postero-inferior wall of the LA, the LA appendage and mitral isthmus [194]. Clinically, atrial tachycardia occurs early after the ablation procedure. One study showed that the average time for occurrence of atrial tachycardia was 3.2 \pm 3.1 months, while other authors noted an early occurrence, between 1-42 days from the procedure, in all patients $[195,200]$. The early occurrence of atrial tachycardia (during the first 3 months) could be mediated by atrial inflammation, while subsequent maturation of ablative lesions in the first weeks after the procedure could lead to spontaneous disappearance of tachycardia in $39 \%-50 \%$ of patients $[3,120,201]$. The early occurrence of atrial arrhythmias after AF ablation could be reduced with antiarrhythmic or anti-inflammatory drugs, and in case of persistent forms, elective cardioversion should be performed [57-59]. Due to longer atrial cycle length, atrial tachycardia is usually followed by faster ventricular response and more severe symptoms than pre-procedural AF [194]. In extreme cases atrial tachycardia could cause progressive tachycardia-induced myocardial dysfunction and congestive HF. Generally, post-procedural atrial tachycardia poorly responds to AAD therapy, thus if atrial tachycardia does not subside spontaneously, it is necessary to perform repeated ablation [200].

Twelve-lead-electrocardiogram is not always reliable in predicting of anatomical origin of tachycardia because P-wave morphology after extended LA ablation could be considerably altered due to modified pathway of atrial activation [194]. The diagnosis is definitely made by an electrophysiological study, through conventional activation mapping and entrainment mapping [196]. The use of 3D-mapping systems may facilitate atrial tachycardia mapping and ablation [195]. Firstly, revision of all PVs as well as ablation lines has to be carried out, because up to $96 \%$ of patients actually suffer from tachycardia mediated by conduction gap at the incomplete ablation line from the first procedure [201].

Completing of the linear lesion and electrophysiological confirmation of bidirectional conduction block at the ablation line are very important for reducing the recurrence rate of atrial tachycardia. Namely, postprocedural rate of atrial tachycardia was 2-2.5 times higher among patients with incomplete linear lesions [202]. Acute success rate of ablation is $86 \%-100 \%$, although during the one-year follow up recurrent atrial tachycardia could be expected in a considerable portion of patients (5\% to 47\%). However, in most of those patients (79\%) a new type of atrial tachycardia was registered [194, 196, 200, 201]. 


\section{CONCLUSION}

Triggers and rotors within the PVs and on the posterior wall of the LA have dominant electrophysiological role in initiation and sustaining of episodes of lone AF. The concept of catheter ablation of $\mathrm{AF}$ consists of electrical isolation of the PVs in paroxysmal AF and an additional LA substrate modification in persistent AF. Creating a durable ablation lesion can be a challenge, and electrical reconnection of the PVs is the most common cause of AF reoccurrence. Long term rhythm control free of AADs is achieved in approximately $80 \%$ of patients, but often, for final result multiple procedures are necessary, especially in patients with persistent AF. Superiority of catheter ablation in comparison to pharmacological treatment comes to the fore in patients with paroxysmal type of the arrhythmia and after a failure of prior drug therapy. At this moment there is no strong evidence that catheter ablation can reduce mortality and risk of stroke. However, successful rhythm control after AF ablation can lead to significant recovery of systolic left ventricular function, especially in patients with true tachycardiomyopathy. In addition, AF ablation improves QoL and symptomatic status of the patients. Due to limited success, frequent need for re-intervention and a $1 \%-4 \%$ risk of life-threatening complications, such as cardiac tamponade, PV stenosis, atrioesophageal fistula or stroke, the procedure is presently reserved for selected AF patients. Younger patients with highly symptomatic paroxysmal lone AF represent the best candidates for the procedure. Although the new regimens of anticoagulation significantly reduce the risk of periprocedural thromboembolism without increasing the risk of bleeding, the optimal long term anticoagulation after the procedure is not clearly defined yet and the individual approach is necessary. The aim of the new technology development is to make ablation simpler, safer and more efficient, and thus feasible in majority of patients with AF. 


\section{REFERENCES}

1. Camm AJ, Kirchhof P, Lip GY, et al. Guidelines for the management of atrial fibrillation. Eur Heart J. 2010; 31: 2369-429

2. Chung SS, Blackshear JL, Shen WK, Hammill SC, Gersh BJ. Epidemiology and natural history of atrial fibrillation: clinical implications. J Am Coll Cardiol 2001; 37: 371-8.

3. Calkins H, Kuck KH, Cappato R, et al. 2012 HRS/EHRA/ECAS expert consensus statement on catheter and surgical ablation of atrial fibrillation: recommendations for patient selection, procedural techniques, patient management and follow-up, definitions, endpoints, and research trial design: a report of the Heart Rhythm Society (HRS) Task Force on Catheter and Surgical Ablation of Atrial Fibrillation. Developed in partnership with the European Heart Rhythm Association (EHRA), a registered branch of the European Society of Cardiology (ESC) and the European Cardiac Arrhythmia Society (ECAS); and in collaboration with the American College of Cardiology (ACC), American Heart Association (AHA), the Asia Pacific Heart Rhythm Society (APHRS), and the Society of Thoracic Surgeons (STS). Endorsed by the governing bodies of the American College of Cardiology Foundation, the American Heart Association, the European Cardiac Arrhythmia Society, the European Heart Rhythm Association, the Society of Thoracic Surgeons, the Asia Pacific Heart Rhythm Society, and the Heart Rhythm Society. Heart Rhythm 2012; 9: 632-96.

4. Markides V, Schilling RJ. Atrial fibrillation: classification, pathophysiology, mechanisms and drug treatment. Heart 2003; 89: 939-43.

5. Bettoni M, Zimmermann M. Autonomic tone variations before the onset of paroxysmal atrial fibrillation. Circulation 2002; 105: 2753-59.

6. Potpara TS, Lip GY. Lone atrial fibrillation: what is known and what is to come. Int J Clin Pract 2011; 65: $446-57$.

7. Haïssaguerre M, Shah DC, Jaïs P, et al. Electrophysiological breakthroughs from the left atrium to the pulmonary veins. Circulation 2000; 102: 2463-5.

8. Higuchi K, Yamauchi Y, Hirao K, Marrouche NF. The importance of superior vena cava isolation in ablation strategy for atrial fibrillation. Curr Opin Cardiol 2013; 28: 2-6.

9. Kumagai K. Catheter Ablation of Atrial Fibrillation. -State of the Art-. Circ J 2011; 75: 2305-11.

10. Tan AY, Li H, Wachsmann-Hogiu S, Chen LS, Chen PS, Fishbein MC. Autonomic innervation and segmental muscular disconnections at the human pulmonary vein-atrial junction: implications for catheter ablation of atrial-pulmonary vein junction. J Am Coll Cardiol 2006; 48: 132-43.

11. Kumagai K, Akimitsu S, Kawahira K, Kawanami F et al. Electrophysiological properties in chronic lone atrial fibrillation. Circulation 1991; 84: 1662-8.

12. Stiles MK, John B, Wong CX, et al. Paroxysmal lone atrial fibrillation is associated with an abnormal atrial substrate. Characterizing the "second factor". J Am Coll Cardiol 2009; 14: 1182-91.

13. Pokushalov E, Turov A, Shugayev P, Artyomenko S, Romanov A, Shirokova N. Catheter ablation of left atrial ganglionated plexi for atrial fibrillation. Asian Cardiovasc Thorac Ann 2008; 16: 194-201. 
14. Todd DM, Skanes AC, Guiraudon G, et al. Role of the posterior left atrium and pulmonary veins in human lone atrial fibrillation: electrophysiological and pathological data from patients undergoing atrial fibrillation surgery. Circulation 2003; 108: 3108-14.

15. Haïssaguerre M, Sanders $\mathrm{P}$, Hocini M, et al. Changes in atrial fibrillation cycle length and inducibility during catheter ablation and their relation to outcome. Circulation 2004; 109: 3007-13.

16. Stiles MK, John B, Wong CX, et al. Paroxysmal lone atrial fibrillation is associated with an abnormal atrial substrate. Characterizing the "Second Factor". J Am Coll Cardiol 2009; 14: 1182-91.

17. Frustaci A, Chimenti C, Belloci F, Morgante E, Russo MA, Maseri A. Histological substrate of atrial biopsies in patients with lone atrial fibrillation. Circulation 1997; 96: 1180-4.

18. Mahnkopf C, Badger TJ, Burgon NS, et al. Evaluation of the left atrial substrate in patients with lone atrial fibrillation using delayed-enhanced MRI: Implications for disease progression and response to catheter ablation. Heart Rhythm 2010; 7: 1475-81.

19. Assasi N, Xie F, Blackhouse G, et al. Comparative effectiveness of catheter ablation strategies for rhythm control in patients with atrial fibrillation: a meta-analysis. J Interv Card Electrophysiol 2012; 35:259-75.

20. Tung R, Buch E, Shivkumar K. Catheter ablation of atrial fibrillation. Circulation 2012; 126: 223-9.

21. Verma A. The techniques for catheter ablation of paroxysmal and persistent atrial fibrillation: a systematic review. Curr Opin Cardiol 2011, 26:17-24.

22. Latchamsetty R, Chugh A. Catheter ablation of persistent atrial fibrillation. J Innov Cardiac Rhythm Management 2013; 1187-1204.

23. Kumagai K. Box isolation for atrial fibrillation. J Arrhythmia 2011; 27: 255-67.

24. Mun H-S, Joung B, Shim J, et al. Does additional linear ablation after circumferential pulmonary vein isolation improve clinical outcome in patients with paroxysmal atrial fibrillation? Prospective randomised study. Heart 2012; 98: 480-4.

25. Haïssaguerre M, Sanders $\mathrm{P}$, Hocini M, at al. Catheter ablation of long-lasting persistent atrial fibrillation: Critical structures for termination. J Cardiovasc Electrophysiol 2005; 11: 1125-37.

26. Wazni O, Wilkoff B, Saliba W. Catheter ablation for atrial fibrillation. N Engl J Med 2011; 365: 2296304.

27. Eitel C, Hindricks G, Sommer P, et al. Circumferential pulmonary vein isolation and linear left atrial ablation as a single-catheter technique to achieve bidirectional conduction block: The pace-and-ablate approach. Heart Rhythm 2010; 7: 157-64.

28. Gaita F, Caponi D, Scaglione M, et al. Long-term clinical results of 2 different ablation strategies in patients with paroxysmal and persistent atrial fibrillation. Circ Arrhythm Electrophysiol 2008; 1: 26975.

29. Ganesan AN, Shipp NJ, Brooks AG, et al. Long-term outcomes of catheter ablation of atrial fibrillation: A systematic review and meta-analysis. J Am Heart Assoc 2013; 2: e004549 doi: 10.1161/JAHA.112.004549

30. Tzeis S, Andrikopoulos G, Deisenhofer I, Ho SY, Theodorakis G. Transseptal catheterization: considerations and caveats. Pacing Clin Electrophysiol 2010; 33: 231-42. 
31. Yao Y, Guo J, Ding L, et al. Improved approach to atrial septum puncture: experience in 539 cases. Chin Med J 2012; 125: 1179-81.

32. Cheng A, Calkins H. A conservative approach to performing transseptal punctures without the use of intracardiac echocardiography: stepwise approach with real-time video clips. J Cardiovasc Electrophysiol 2007; 18: 686-9.

33. Gard J, Swale M, Asirvatham SJ. Transseptal access for the electrophysiologist: anatomic considerations to enhance safety and efficacy. J Innov Cardiac Rhythm Management 2011; 2: 332-8.

34. Haines D. Biophysics of ablation: application to technology. J Cardiovasc Electrophysiol 2004; 15: 211.

35. Nakagawa H, Yamanashi W, Pitha JV, et al. Comparison of in vivo tissue temperature profile and lesion geometry for radiofrequency ablation with a saline-irrigated electrode versus temperature control in a canine thigh muscle preparation. Circulation 1995; 91: 2264-73.

36. Andrade J, Dubuc M, Guerra P, et al. The biophysics and biomechanics of cryoballoon ablation. Pacing Clin Electrophysiol 2012; 35: 1162-8.

37. Andrade JG, Khairy P, Dubuc M. Catheter cryoablation biology and clinical uses. Circ Arrhythm Electrophysiol 2013; 6: 218-27.

38. Beukema RP, Beukema WP, Smit JJ, et al. Efficacy of multi-electrode duty-cycled radiofrequency ablation for pulmonary vein disconnection in patients with paroxysmal and persistent atrial fibrillation. Europace 2010; 12: 502-7.

39. Mulder AW, Balt JC, Wijffels MC, et al. Safety of pulmonary vein isolation and left atrial complex fractionated atrial electrograms ablation for atrial fibrillation with phased radiofrequency energy and multi-electrode catheters. Europace 2012; 14: 1433-40.

40. Oral H, Knight BP, Tada H, et al. Pulmonary vein isolation for paroxysmal and persistent atrial fibrillation. Circulation 2002; 105: 1077-81.

41. Pappone C, Oreto G, Rosanio S, et al. Atrial electroanatomic remodeling after circumferential radiofrequency pulmonary vein ablation. Efficacy of an anatomic approach in a large cohort of patients with atrial fibrillation. Circulation 2001; 104: 2539-44.

42. Ouyang F, Bänsch D, Ernst S, et al. Complete isolation of left atrium surrounding the pulmonary veins: new insights from the double-lasso technique in paroxysmal atrial fibrillation. Circulation 2004; 110: 2090-6.

43. Arentz T, Weber R, Bürkle G, et al. Small or large isolation areas around the pulmonary veins for the treatment of atrial fibrillation? Results from a prospective randomized study. Circulation 2007; 115: 3057-63.

44. Kiuchi K, Kircher S, Watanabe N, et al. Quantitative analysis of isolation area and rhythm outcome in patients with paroxysmal atrial fibrillation after circumferential pulmonary vein antrum isolation using the pace-and-ablate technique. Circ Arrhythm Electrophysiol 2012; 5: 667-75.

45. Yamada T, Yoshida N, Murakami Y, et al. The difference in autonomic denervation and its effect on atrial fibrillation recurrence between the standard segmental and circumferential pulmonary vein isolation techniques. Europace 2009; 11: 1612-9. 
46. Seaborn GEJ, Todd K, Michael KA, et al. Heart rate variability and procedural outcome in catheter ablation for atrial fibrillation. Ann Noninvasive Electrocardiol 2013; 00: 1-11.

47. Ouyang F, Tilz R, Chun J, et al. Long-term results of catheter ablation in paroxysmal atrial fibrillation: lessons from a 5-year follow-up. Circulation 2010; 122: 2368-77.

48. Chen S-A, Tai C-T. Catheter ablation of atrial fibrillation originating from the non-pulmonary vein foci. J Cardiovasc Electrophysiol 2005; 16: 229-32.

49. Higuchi K, Yamauchi Y, Hirao K, Marrouche NF. The importance of superior vena cava isolation in ablation strategy for atrial fibrillation. Curr Opin Cardiol 2013; 28: 2-6.

50. Nademanee K, McKenzie J, Erol Kosar E, et al. A new approach for catheter ablation of atrial fibrillation: mapping of the electrophysiologic substrate. J Am Coll Cardiol 2004; 43: 2044 -53.

51. Caldwell J, Redfearn D. Ablation of complex fractionated atrial electrograms in catheter ablation for AF; where have we been and where are we going? Curr Cardiol Rev 2012; 8: 347-53.

52. Hocini M, Jaïs P, Sanders P, et al. Techniques, evaluation, and consequences of linear block at the left atrial roof in paroxysmal atrial fibrillation: a prospective randomized study. Circulation 2005; 112 : 3688-96.

53. Jaïs P, Hocini M, Hsu L-F, et al. Technique and results of linear ablation at the mitral isthmus. Circulation 2004; 110; 2996-3002.

54. Willems S, Klemm H, Rostock T, et al. Substrate modification combined with pulmonary vein isolation improves outcome of catheter ablation in patients with persistent atrial fibrillation: a prospective randomized comparison. Eur Heart J 2006; 27: 2871-8.

55. Matsuo S, Yamane T, Date T, et al. Substrate modification by pulmonary vein isolation and left atrial linear ablation in patients with persistent atrial fibrillation: its impact on complex-fractionated atrial electrograms. J Cardiovasc Electrophysiol 2012; 23: 962-70.

56. Pokushalov E, Romanov A, Artyomenko S, et al. Ganglionated plexi ablation for longstanding persistent atrial fibrillation. Europace 2010; 12: 342-6.

57. Deftereos S, Giannopoulos G, Kossyvakis C, et al. Colchicine for prevention of early atrial fibrillation recurrence after pulmonary vein isolation: a randomized controlled study. J Am Coll Cardiol 2012; 60: 1790-6.

58. Koyama T, Tada H, Sekiguchi Y, et al. Prevention of atrial fibrillation recurrence with corticosteroids after radiofrequency catheter ablation: a randomized controlled trial. J Am Coll Cardiol 2010;56: 1463 72.

59. Roux J-F, Zado E, Callans DJ, et al. Antiarrhythmics after ablation of atrial fibrillation (5A Study). Circulation 2009; 120: 1036-40.

60. Namdar M, Chierchia GB, Westra S, et al. Isolating the pulmonary veins as first-line therapy in patients with lone paroxysmal atrial fibrillation using the cryoballoon. Europace 2012; 14: 197-203.

61. Furlanello F, Lupo P, Pittalis M, et al. Radiofrequency catheter ablation of atrial fibrillation in athletes referred for disabling symptoms preventing usual training schedule and sport competition. J Cardiovasc Electrophysiol 2008; 19: 457-62.

62. Miyazaki S, Kobori A, Hocini M, et al. Clinical utility of adenosine-infusion test at a repeat atrial fibrillation ablation procedure. Heart Rhythm 2013; 10: 629-35. 
63. McLellan AJ, Kumar S, Smith C, et al. The role of adenosine following pulmonary vein isolation in patients undergoing catheter ablation for atrial fibrillation: a systematic review. J Cardiovasc Electrophysiol 2013; 24: 742-51.

64. Jiang CY, Jiang RH, Matsuo S, et al. Early detection of pulmonary vein reconnection after isolation in patients with paroxysmal atrial fibrillation: a comparison of ATP-induction and reassessment at 30 minutes postisolation. J Cardiovasc Electrophysiol 2009; 20: 1382-7.

65. Neuzil P, Reddy VY, Kautzner J, et al. Electrical reconnection after pulmonary vein isolation is contingent on contact force during initial treatment: results from the EFFICAS I study. Circ Arrhythm Electrophysiol 2013; 6: 327-33.

66. Reddy VY, Shah D, Kautzner J, et al. The relationship between contact force and clinical outcome during radiofrequency catheter ablation of atrial fibrillation in the TOCCATA study. Heart Rhythm 2012; 9: 1789-95.

67. Steven D, Sultan A, Reddy V, et al. Benefit of pulmonary vein isolation guided by loss of pace capture on the ablation line: results from a prospective 2-center randomized trial. J Am Coll Cardiol 2013; 62: 44-50.

68. Bortone A, Appetiti A, Bouzeman A, et al. Unipolar signal modification as a guide for lesion creation during radiofrequency application in the left atrium prospective study in humans in the setting of paroxysmal atrial fibrillation catheter ablation. Circ Arrhythm Electrophysiol 2013; 6: 1095-102.

69. Sartini RJP, Scanavacca MI, Sosa E, et al. Radiofrequency ablation of paroxysmal atrial fibrillation: factors determining long-term clinical efficacy. Arq Bras Cardiol 2008; 90:112-8.

70. Fiala M, Chovančík J, Nevřalová R, et al. Pulmonary vein isolation using segmental versus electroanatomical circumferential ablation for paroxysmal atrial fibrillation. J Interv Card Electrophysiol 2008; 22: 13-21.

71. Medi C, Sparks PB, Morton JB, et al. Pulmonary vein antral isolation for paroxysmal atrial fibrillation: results from long-term follow-up. J Cardiovasc Electrophysiol 2011; 22: 137-41.

72. Matsuo S, Yamane T, Date T, et al. Dormant pulmonary vein conduction induced by adenosine in patients with atrial fibrillation who underwent catheter ablation. Am Heart J 2011; 161: 188-96.

73. Weerasooriya R, Khairy P, Litalien J, et al. Catheter ablation for atrial fibrillation: are results maintained at 5 years of follow-up? J Am Coll Cardiol 2011; 11: 57:160-6.

74. Hussein AA, Saliba WI, Martin DO, et al. Natural history and long-term outcomes of ablated atrial fibrillation. Circ Arrhythm Electrophysiol 2011; 4: 271-8.

75. Vogt J, Heintze J, Gutleben KJ, Muntean B, Horstkotte D, Nölker G. Long-term outcomes after cryoballoon pulmonary vein isolation. Results from a prospective study in 605 patients. J Am Coll Cardiol 2013; 61: 1707-12.

76. Hsieh M-H, Tai C-T, Lee S-H, et al. The different mechanisms between late and very late recurrences of atrial fibrillation in patients undergoing a repeated catheter ablation. J Cardiovasc Electrophysiol 2006; 17: 231-5.

77. Tzou WS, Marchlinski FE, Zado ES, et al. Long-term outcome after successful catheter ablation of atrial fibrillation. Circ Arrhythm Electrophysiol 2010; 3: 237-42. 
78. Shah AN, Mittal S, Sichrovsky TC, et al. Long-term outcome following successful pulmonary vein isolation: pattern and prediction of very late recurrence. J Cardiovasc Electrophysiol 2008; 19: 661-7.

79. Bertaglia E, Tondo C, De Simone A, et al. Does catheter ablation cure atrial fibrillation? Singleprocedure outcome of drug-refractory atrial fibrillation ablation: a 6-year multicentre experience. Europace 2010; 12: 181-7.

80. Mainigi SK, Sauer WH, Cooper JM, et al. Incidence and predictors of very late recurrence of atrial fibrillation after ablation. J Cardiovasc Electrophysiol 2007; 18: 69-74.

81. Letsas KP, Efremidis M, Giannopoulos G, et al. CHADS2 and CHA2DS2-VASc scores as predictors of left atrial ablation outcomes for paroxysmal atrial fibrillation. Europace 2014; 16: 202-7.

82. Arya A, Hindricks G, Sommer P, et al. Long-term results and the predictors of outcome of catheter ablation of atrial fibrillation using steerable sheath catheter navigation after single procedure in 674 patients. Europace 2010; 12: 173-80.

83. Khaykin Y, Oosthuizen R, Zarnett L, et al. Clinical predictors of arrhythmia recurrences following pulmonary vein antrum isolation for atrial fibrillation: predicting arrhythmia recurrence post-PVAI. J Cardiovasc Electrophysiol 2011; 22: 1206-14.

84. Fein AS, Shvilkin A, Shah D, et al. Treatment of obstructive sleep apnea reduces the risk of atrial fibrillation recurrence after catheter ablation. J Am Coll Cardiol 2013; 62: 300-5.

85. Verma A, Kilicaslan F, Pisano E, et al. Response of atrial fibrillation to pulmonary vein antrum isolation is directly related to resumption and delay of pulmonary vein conduction. Circulation 2005; 112: 627-35.

86. Potpara TS, Stankovic GR, Beleslin BD, et al. A 12-year follow-up study of patients with newly diagnosed lone atrial fibrillation. Implications of arrhythmia progression on prognosis: The Belgrade Atrial Fibrillation Study. Chest 2012; 141: 339-47.

87. Roy D, Talajic M, Nattel S, et al. Rhythm control versus rate control for atrial fibrillation and heart failure. N Engl J Med 2008; 358: 2667-77.

88. Hohnloser SH, Kuck KH, Lilienthal J. Rhythm or rate control in atrial fibrillation-pharmacological intervention in atrial fibrillation (PIAF): a randomized trial. Lancet 2000; 356: 1789-94.

89. Corley SD, Epstein AE, DiMarco JP, et al. Relationships between sinus rhythm, treatment, and survival in the Atrial Fibrillation Follow-Up Investigation of Rhythm Management (AFFIRM) Study. Circulation 2004; 109: 1509-13.

90. Wazni OM, Marrouche NF, Martin DO, et al. Radiofrequency ablation vs antiarrhythmic drugs as firstline treatment of symptomatic atrial fibrillation a randomized trial. JAMA 2005; 293: 2634-40.

91. Stabile G, Bertaglia E, Senatore G, et al. Catheter ablation treatment in patients with drug-refractory atrial fibrillation: a prospective,multi-centre, randomized, controlled study (Catheter Ablation For The Cure Of Atrial Fibrillation Study). Eur Heart J 2006; 27: 216-21.

92. Oral H, Pappone C, Chugh A, et al. Circumferential pulmonary-vein ablation for chronic atrial fibrillation. N Engl J Med 2006; 354: 934-41.

93. Jaïs $\mathrm{P}$, Cauchemez B, Macle L, et al. Catheter ablation versus antiarrhythmic drugs for atrial fibrillation: The A4 Study. Circulation 2008; 118: 2498-505. 
94. Forleo GB, Mantica M, De Luca L, et al. Catheter ablation of atrial fibrillation in patients with diabetes mellitus type 2: results from a randomized study comparing pulmonary vein isolation versus antiarrhythmic drug therapy. J Cardiovasc Electrophysiol 2009; 20: 22-8.

95. Wilber DJ, Pappone C, Neuzil P, et al. Comparison of antiarrhythmic drug therapy and radiofrequency catheter ablation in patients with paroxysmal atrial fibrillation: a randomized controlled trial. JAMA 2010; 303: 333-40.

96. Pappone C, Augello G, Sala S, et al. A randomized trial of circumferential pulmonary vein ablation versus antiarrhythmic drug therapy in paroxysmal atrial fibrillation: the APAF study. J Am Coll Cardiol 2006; 48: 2340-7.

97. Pappone C, Vicedomini G, Augello G, et al. Radiofrequency catheter ablation and antiarrhythmic drug therapy: a prospective, randomized, 4-year follow-up trial: the APAF study. Circ Arrhythm Electrophysiol 2011; 4: 808-14.

98. Nielsen JC, Johannessen A, Raatikainen P, et al. Radiofrequency ablation as initial therapy in paroxysmal atrial fibrillation. N Engl J Med 2012; 367: 1587-95.

99. Mont L, Bisbal F, Hernandez-Madrid A, et al. Catheter ablation vs. antiarrhythmic drug treatment of persistent atrial fibrillation: a multicentre, randomized, controlled trial (SARA study). Eur Heart J 2013; doi:10.1093/eurheartj/eht457

100. Pokushalov E, Romanov A, De Melis M, et al. Progression of atrial fibrillation after a failed initial ablation procedure in patients with paroxysmal atrial fibrillation: a randomized comparison of drug therapy versus reablation. Circ Arrhythm Electrophysiol 2013; 6: 754-60.

101. Noheria A, Kumar A, Wylie Jr JV, Josephson ME. Catheter ablation vs antiarrhythmic drug therapy for atrial fibrillation: a systematic review. Arch Intern Med 2008; 168: 581-6.

102. Bonanno C, Paccanaro M, La Vecchia L, et al. Efficacy and safety of catheter ablation versus antiarrhythmic drugs for atrial fibrillation: a meta-analysis of randomized trials. J Cardiovasc Med 2010; 11: 408-18.

103. Dagres N, Varounis C, Flevari P, et al. Mortality after catheter ablation for atrial fibrillation compared with antiarrhythmic drug therapy. A meta-analysis of randomized trials. Am Heart J 2009; 158: 15-20.

104. Pappone C, Rosanio S, Augello G, et al. Mortality, morbidity, and quality of life after circumferential pulmonary vein ablation for atrial fibrillation. J Am Coll Cardiol 2003; 42: 185-97.

105. Nademanee K, Schwab MC, Kosar EM, et al. Clinical outcomes of catheter substrate ablation for highrisk patients with atrial fibrillation. J Am Coll Cardiol 2008; 51: 843-9.

106. Hunter RJ, McCready J, Diab I, et al. Maintenance of sinus rhythm with an ablation strategy in patients with atrial fibrillation is associated with a lower risk of stroke and death. Heart 2012; 98: 48-53.

107. Lin Y-J, Chao T-F, Tsao H-M et al. Successful catheter ablation reduces the risk of cardiovascular events in atrial fibrillation patients with $\mathrm{CHA}_{2} \mathrm{DS}_{2}$-VASc risk score of 1 and higher. Europace 2013; 15: 676-84.

108. De Vos CB, Pisters R, Nieuwlaat R, et al. Progression from paroxysmal to persistent atrial fibrillation: clinical correlates and prognosis. J Am Coll Cardiol 2010; 55: 725-31.

109. Jahangir A, Lee V, Friedman PA, et al. Long-term progression and outcomes with aging in patients with lone atrial fibrillation: a 30-year follow-up study. Circulation 2007; 115: 3050-6. 
110. Jongnarangsin K, Suwanagool A, Chugh A, et al. Effect of catheter ablation on progression of paroxysmal atrial fibrillation. J Cardiovasc Electrophysiol 2012; 23: 9-14.

111. Kerr CR, Humphries KH, Talajic M, et al. Progression to chronic atrial fibrillation after the initial diagnosis of paroxysmal atrial fibrillation: Results from the Canadian Registry of Atrial Fibrillation. Am Heart J 2005; 149: 489-96.

112. Anter E, Jessup M , Callans DJ, et al. Atrial fibrillation and heart failure: treatment considerations for a dual epidemic. Circulation 2009; 119: 2516-25.

113. Man J, Marchlinski FE. Atrial fibrillation ablation and heart failure. Curr Cardiol Rep 2012; 14:571-6.

114. Gentlesk PJ, Sauer WH, Gerstenfeld EP, et al. Reversal of left ventricular dysfunction following ablation of atrial fibrillation. J Cardiovasc Electrophysiol 2007; 18: 9-14.

115. Hsu L-F, Jaïs $\mathrm{P}$, Sanders $\mathrm{P}$, et al. Catheter ablation for atrial fibrillation in congestive heart failure. $\mathrm{N}$ Engl J Med 2004; 351: 2373-83.

116. Lutomsky BA, Rostock T, Koops A, et al. Catheter ablation of paroxysmal atrial fibrillation improves cardiac function: a prospective study on the impact of atrial fibrillation ablation on left ventricular function assessed by magnetic resonance imaging. Europace 2008; 10:593-9.

117. Anselmino M, Grossi S, Scaglione M, et al. Long-term results of transcatheter atrial fibrillation ablation in patients with impaired left ventricular systolic function. J Cardiovasc Electrophysiol 2013; 24: 24-32.

118. Wokhlu A, Monahan KH, Hodge DO, et al. Long-term quality of life after ablation of atrial fibrillation the impact of recurrence, symptom relief, and placebo effect. J Am Coll Cardiol 2010; 55: 2308-16.

119. Reynolds MR, Walczak J, White SA, Cohen DJ, Wilber DJ. Improvements in symptoms and quality of life in patients with paroxysmal atrial fibrillation treated with radiofrequency catheter ablation versus antiarrhythmic drugs. Circ Cardiovasc Qual Outcomes 2010; 3: 615-23.

120. Raviele A, Natale A, Calkins H, et al. Venice Chart international consensus document on atrial fibrillation ablation: 2011 Update. J Cardiovasc Electrophysiol, 23: 890-923.

121. Anné W, Tavernier R, Duytschaever M. Four types of complications in paroxysmal atrial fibrillation ablation. Europace 2010; 12: 303-4.

122. Cappato R, Calkins H, Chen S-A, et al. Worldwide Survey on the methods, efficacy, and safety of catheter ablation for human atrial fibrillation. Circulation 2005; 111: 1100-05.

123. Cappato R, Calkins H, Chen S-A, et al. Updated Worldwide Survey on the methods, efficacy, and safety of catheter ablation for human atrial fibrillation. Circ Arrhythm Electrophysiol 2010; 3: 32-8.

124. Gupta A, Perera T, Ganesan A, et al. Complications of catheter ablation of atrial fibrillation: a systematic review. Circ Arrhythm Electrophysiol 2013; 6: 1082-8.

125. Lee G, Sparks PB, Morton JB, et al. Low risk of major complications associated with pulmonary vein antral isolation for atrial fibrillation: results of 500 consecutive ablation procedures in patients with low prevalence of structural heart disease from a single center. J Cardiovasc Electrophysiol 2011; 22: 163-8.

126. Zado E, Callans DJ, Riley M, et al. Long-term clinical efficacy and risk of catheter ablation for atrial fibrillation in the elderly. J Cardiovasc Electrophysiol 2008; 19: 621-6.

127. Spragg DD, Dalal D, Cheema A, et al. Complications of catheter ablation for atrial fibrillation: incidence and predictors. J Cardiovasc Electrophysiol 2008; 19: 627-31. 
128. Dagres N, Hindricks G, Kottkamp H, et al. Complications of atrial fibrillation ablation in a high-volume center in 1,000 procedures: still cause for concern? J Cardiovasc Electrophysiol 2009; 20: 1014-9.

129. Hoffmann BA, Kuck K-H, Andresen D, et al. Impact of structural heart disease on the acute complication rate in atrial fibrillation ablation: results from the German ablation registry. J Cardiovasc Electrophysiol 2014; 25: 242-9.

130. Baman TS, Jongnarangsin K, Chugh A, at al. Prevalence and predictors of complications of radiofrequency catheter ablation for atrial fibrillation. J Cardiovasc Electrophysiol 2011; 22: 626-31.

131. Santangeli P, Di Biase L, Pelargonio G, Natale A. Outcome of invasive electrophysiological procedures and gender: are males and females the same? J Cardiovasc Electrophysiol 2011; 22: 605-12.

132. Shoemaker MB, Muhammad R, Farrell M, et al. Relation of morbid obesity and female gender to risk of procedural complications in patients undergoing atrial fibrillation ablation. Am J Cardiol 2013; 111 : 368-73.

133. Aldhoon B, Wichterle D, Peichl P, Čihak R, Kautzner J. Complications of catheter ablation for atrial fibrillation in a high-volume centre with the use of intracardiac echocardiography. Europace 2013; 15 : 24-32.

134. Bertaglia E, Zoppo F, Tondo C, et al. Early complications of pulmonary vein catheter ablation for atrial fibrillation: a multicenter prospective registry on procedural safety. Heart Rhythm 2007; 4: 1265-71.

135. Hsu L-F, Jais P, Hocini M, et al. Incidence and prevention of cardiac tamponade complicating ablation for atrial fibrillation. Pacing Clin Electrophysiol 2005; 28: 106-9.

136. Schmidt M, Dorwarth U, Andresen D, et al. Cryoballoon versus RF ablation in paroxysmal atrial fibrillation: results from the German ablation registry. J Cardiovasc Electrophysiol 2014; 25: 1-7.

137. Deshmukh A, Patel NJ, Pant S, et al. In-hospital complications associated with catheter ablationof atrial fibrillation in the United States between 2000 and 2010: analysis of 93801 procedures. Circulation 2013; 128: 2104-12.

138. Cappato R, Calkins H, Chen SA, et al. Prevalence and causes of fatal outcome in catheter ablation of atrial fibrillation. J Am Coll Cardiol 2009; 53: 1798-803.

139. Bunch TJ, Asirvatham SJ, Friedman PA, et al. Outcomes after cardiac perforation during radiofrequency ablation of the atrium. J Cardiovasc Electrophysiol 2005; 16: 1172-9.

140. Burkhardt JD, Natale A. New technologies in atrial fibrillation ablation. Circulation 2009; 120: 1533 41.

141. Muth JN, Costea A, Attari M. Autologous blood transfusion in a patient with pericardial tamponade during atrial fibrillation ablation. J Inovations Card Rhythm Mange 2012; 3: 973-5.

142. O’Neill MD, Jais P, Derval N, Hocini M, Haissaguerre M. Two techniques to avoid surgery for cardiac tamponade occurring during catheter ablation of atrial fibrillation. J Cardiovasc Electrophysiol 2008; 19: 323-5.

143. Floria M, De Roy L, Xhaet O, et al. Predictive value of thromboembolic risk scores before an atrial fibrillation ablation procedure. J Cardiovasc Electrophysiol 2013; 24: 139-45.

144. McCready JW, Nunn L, Lambiase PD, et al. Incidence of left atrial thrombus prior to atrial fibrillation ablation: is pre-procedural transoesophageal echocardiography mandatory? Europace 2010; 12: 927-32. 
145. Kirubakaran S, Zuberi Z, Gill J. Acute myocardial infarction due to a coronary embolus during left atrial ablation for persistent atrial fibrillation. Europace 2013; 15: 211.

146. Scherr D, Sharma K, Dalal D, et al. Incidence and predictors of periprocedural cerebrovascular accident in patients undergoing catheter ablation of atrial fibrillation. J Cardiovasc Electrophysiol 2009; 20: 1357-63.

147. Patel D, Bailey SM, Furlan AJ, et al. Long-term functional and neurocognitive recovery in patients who had an acute cerebrovascular event secondary to catheter ablation for atrial fibrillation. J Cardiovasc Electrophysiol 2010; 21: 412-7.

148. Gaita F, Caponi D, Pianelli M, et al. Radiofrequency catheter ablation of atrial fibrillation: a cause of silent thromboembolism? Magnetic resonance imaging assessment of cerebral thromboembolism in patients undergoing ablation of atrial fibrillation. Circulation 2010; 122: 1667-73.

149. Merchant FM, Delurgio DB. Catheter ablation of atrial fibrillation and risk of asymptomatic cerebral embolism. Pacing Clin Electrophysiol 2014; 37: 389-97.

150. Hoyt H, Bhonsale A, Chilukuri K, et al. Complications arising from catheter ablation of atrial fibrillation: Temporal trends and predictors. Heart Rhythm 2011; 8: 1869-74.

151. Cauchemez B, Extramiana F, Cauchemez S, et al. High-flow perfusion of sheaths for prevention of thromboembolic complications during complex catheter ablation in the left atrium. J Cardiovasc Electrophysiol 2004; 15: 276-83.

152. Gaita F, Leclercq JF, Schumacher B, et al. Incidence of silent cerebral thromboembolic lesions after atrial fibrillation ablation may change according to technology used: comparison of irrigated radiofrequency, multipolar nonirrigated catheter and cryoballoon. J Cardiovasc Electrophysiol 2011; 22: $961-8$.

153. Siklody CH, Deneke T, Hocini M, et al. Incidence of asymptomatic intracranial embolic events after pulmonary vein isolation: comparison of different atrial fibrillation ablation technologies in a multicenter study. J Am Coll Cardiol 2011; 58: 681-8.

154. Neumann T, Kuniss M, Conradi G, et al. MEDAFI-Trial (Micro-embolization during ablation of atrial fibrillation): comparison of pulmonary vein isolation using cryoballoon technique vs. radiofrequency energy. Europace 2011; 13: 37-44.

155. Martinek M, Sigmund E, Lemes C, et al. Asymptomatic cerebral lesions during pulmonary vein isolation under uninterrupted oral anticoagulation. Europace 2013; 15: 325-31.

156. Chao T-F, Lin Y-J, Tsao H-M, et al. CHADS2 and $\mathrm{CHA}_{2} \mathrm{DS}_{2}-\mathrm{VASc}$ scores in the prediction of clinical outcomes in patients with atrial fibrillation after catheter ablation. J Am Coll Cardiol; 2011: 58: 2380-5.

157. Kornej J, Hindricks G, Kosiuk J, et al. Renal dysfunction, stroke risk scores $\left(\mathrm{CHADS}_{2}, \mathrm{CHA}_{2} \mathrm{DS}_{2^{-}}\right.$ VASc, and $\mathrm{R}_{2} \mathrm{CHADS}_{2}$ ), and the risk of thromboembolic events after catheter ablation of atrial fibrillation: the Leipzig Heart Center AF Ablation Registry. Circ Arrhythm Electrophysiol 2013; 6: 868-74.

158. Verma A, Tsang B. The use of anticoagulation during the periprocedure period of atrial fibrillation ablation. Curr Opin Cardiol 2012; 27: 55-61.

159. Bunch TJ, Crandall BG, Weiss JP, et al. Warfarin is not needed in low-risk patients following atrial fibrillation ablation procedures. J Cardiovasc Electrophysiol; 20: 988-93. 
160. Santangeli P, Di Biase L, Horton R, et al. Ablation of atrial fibrillation under therapeutic warfarin reduces periprocedural complications: evidence from a meta-analysis. Circ Arrhythm Electrophysiol 2012; 5: 302-11.

161. Kuwahara T, Takahashi A, Takahashi Y, et al. Prevention of periprocedural ischemic stroke and management of hemorrhagic complications in atrial fibrillation ablation under continuous warfarin administration. J Cardiovasc Electrophysiol 2013; 24: 510-5.

162. Steinberg BA, Hasselblad V, Atwater BD, et al. Dabigatran for periprocedural anticoagulation following radiofrequency ablation for atrial fibrillation: a meta-analysis of observational studies. $\mathbf{J}$ Interv Card Electrophysiol 2013; 37: 213-21.

163. Shurrab M, Morillo CA, Schulman S, et al. Safety and efficacy of dabigatran compared with warfarin for patients undergoing radiofrequency catheter ablation of atrial fibrillation: a meta-analysis. Can $\mathbf{J}$ Cardiol 2013; 29: 1203-10.

164. Lakkireddy D, Reddy YM, Di Biase L, et al. Feasibility \& safety of uninterrupted rivaroxaban for periprocedural anticoagulation in patients undergoing radiofrequency ablation for atrial fibrillation: results from a multicenter prospective registry ONLINE FIRST. J Am Coll Cardiol. 2014;(): doi:10.1016/j.jacc.2013.11.039

165. Gautam S, John RM, Stevenson WG, et al. Effect of therapeutic INR on activated clotting times, heparin dosage, and bleeding risk during ablation of atrial fibrillation. J Cardiovasc Electrophysiol 2011; 22: 248-54.

166. Wazni OM, Rossillo A, Marrouche NF, et al. Embolic events and char formation during pulmonary vein isolation in patients with atrial fibrillation: impact of different anticoagulation regimens and importance of intracardiac echo imaging. J Cardiovasc Electrophysiol 2005; 16: 576-81.

167. Ren J-F, Marchlinski FE, Callans DJ, et al. Increased intensity of anticoagulation may reduce risk of thrombus during atrial fibrillation ablation procedures in patients with spontaneous echo contrast. J Cardiovasc Electrophysiol 2005; 16: 474-7.

168. Eitel C, Hindricks G. Does catheter ablation eliminate the need for oral anticoagulation? Circ Arrhythm Electrophysiol 2011; 4: 595-7.

169. Arentz T, Jander N, von Rosenthal J, et al. Incidence of pulmonary vein stenosis 2 years after radiofrequency catheter ablation of refractory atrial fibrillation. European Heart Journal 2003; 24: 963 9.

170. Holmes DR, Monahan KH, Packer D. Pulmonary vein stenosis complicating ablation for atrial fibrillation: clinical spectrum and interventional considerations. J Am Coll Cardiol Intv 2009; 2: 26776.

171. Packer DL, Keelan P, Munger TM, et al. Clinical presentation, investigation, and management of pulmonary vein stenosis complicating ablation for atrial fibrillation. Circulation 2005; 111: 546-54.

172. Prieto LR, Schoenhagen P, Arruda MJ, Natale A, Worley SE. Comparison of stent versus balloon angioplasty for pulmonary vein stenosis complicating pulmonary vein isolation. J Cardiovasc Electrophysiol 2008; 19: 673-8.

173. Neumann T, Vogt J, Schumacher B, et al. Circumferential pulmonary vein isolation with the cryoballoon technique: results from a prospective 3-center study. J Am Coll Cardiol 2008; 52: 273-8. 
174. Neumann T, Kuniss M, Conradi G, et al. Pulmonary vein stenting for the treatment of acquired severe pulmonary vein stenosis after pulmonary vein isolation: clinical implications after long-term follow-up of 4 years. J Cardiovasc Electrophysiol 2009; 20: 251-7.

175. Baranowski B, Saliba W. Our approach to management of patients with pulmonary vein stenosis following AF ablation. J Cardiovasc Electrophysiol 2011; 22: 364-7.

176. Nair GM, Nery PB, Redpath C, et al. Atrio-esophageal fistula in the era of atrial fibrillation ablation: a review. Can J Cardiol 2014; doi: 10.1016/j.cjca.2013.12.012.

177. Di Biase L, Dodig M, Saliba W, et al. Capsule endoscopy in examination of esophagus for lesions after radiofrequency catheter ablation:a potential tool to select patients with increased risk of complications. J Cardiovasc Electrophysiol 2010; 21: 839-44.

178. Eitel C, Rolf S, Zachäus M, et al. Successful nonsurgical treatment of esophagopericardial fistulas after atrial fibrillation catheter ablation: a case series. Circ Arrhythm Electrophysiol 2013; 6: 675-81.

179. Cummings JE, Schweikert RA, Saliba WI, et al. Brief communication: Atrial-esophageal fistulas after radiofrequency ablation. Ann Intern Med 2006; 144: 572-4.

180. Zellerhoff S, Lenze F, Eckardt L. Prophylactic proton pump inhibition after atrial fibrillation ablation: is there any evidence? Europace 2011; 13: 1219-21.

181. Singh SM, d'Avila A, Doshi SK, et al. Esophageal injury and temperature monitoring during atrial fibrillation ablation. Circ Arrhythm Electrophysiol 2008; 1: 162-8.

182. Evonich III RF, Nori DM, Haines DE. A randomized trial comparing effects of radiofrequency and cryoablation on the structural integrity of esophageal tissue. J Interv Card Electrophysiol 2007; 19: 7783.

183. Stöckigt F, Schrickel JW, Andrié R, Lickfett L. Atrioesophageal fistula after cryoballoon pulmonary vein isolation. J Cardiovasc Electrophysiol 2012; 23: 1254-7.

184. Cury RC, Abbara S, Schmidt S et al. Relationship of the esophagus and aorta to the left atrium and pulmonary veins: implications for catheter ablation of atrial fibrillation. Heart Rhythm 2005; 2: 1317 23.

185. Kuwahara T, Takahashi A, Takahashi Y, et al. Clinical characteristics and management of periesophageal vagal nerve injury complicating left atrial ablation of atrial fibrillation: lessons from eleven cases. J Cardiovasc Electrophysiol 2013; 24: 847-51.

186. Wong KC, Lim C, Sadarmin PP, et al. High incidence of acute sub-clinical circumflex artery 'injury' following mitral isthmus ablation. Eur Heart J 2011; 32: 1881-90.

187. Takahashi Y, Jaïs $\mathrm{P}$, Hocini M, et al. Acute occlusion of the left circumflex coronary artery during mitral isthmus linear ablation. J Cardiovasc Electrophysiol 2005; 16: 1104-7.

188. Meissner A, Borchard R, Maagh P, et al. Impact of irrigated energy application on the right coronary artery hemodynamics: FFR measurement in patients who underwent ablation of common type atrial flutter. J Interv Card Electrophysiol 2008; 21: 35-42.

189. Castellanos E, Almendral J. Acute right coronary artery occlusion during cooled-tip radiofrequency ablation of the cavotricuspid isthmus. Indian Pacing Electrophysiol J 2013; 13: 76-9.

190. Sacher F, Jais P, Stephenson K, et al. Phrenic nerve injury after catheter ablation of atrial fibrillation. Indian Pacing Electrophysiol J 2006; 7: 1-6. 
191. Hermida J-S, Traulle S, Kubala M. Left phrenic nerve injury after cryoballoon ablation of the pulmonary veins. Europace 2013; 15: 514.

192. Andrade JG, Dubuc M, Guerra PG, et al. Cryoballoon ablation for atrial fibrillation. Indian Pacing Electrophysiol J 2012; 12: 39-53.

193. Prudente LA, Moorman R, Lake D, et al. Femoral vascular complications following catheter ablation of atrial fibrillation. J Interv Card Electrophysiol 2009; 26: 59-64.

194. Shah AJ, Jadidi A, Liu X, et al. Atrial tachycardias arising from ablation of atrial fibrillation: a proarrhythmic bump or an antiarrhythmic turn? Cardiol Res Pract 2010; 2010: 950763. doi: 10.4061/2010/950763.

195. Ouyang F, Ernst S, Chun J, et al. Electrophysiological findings during ablation of persistent atrial fibrillation with electroanatomic mapping and double lasso catheter technique. Circulation 2005; 112: 3038-48.

196. Castrejon-Castrejon S, Marta Ortega M, Perez-Silva A, et al. Organized atrial tachycardias after atrial fibrillation ablation. Cardiol Res Pract 2011; 1-16.

197. Porter M, Spear W, Akar JG, et al. Prospective study of atrial fibrillation termination during ablation guided by automated detection of fractionated electrograms. J Cardiovasc Electrophysiol 2008; 19: 61320.

198. Wasmer K, Mönnig G, Bittner A, et al. Incidence, characteristics, and outcome of left atrial tachycardias after circumferential antral ablation of atrial fibrillation. Heart Rhythm 2012; 9: 1660-6.

199. Chae S, Oral H, Good E, et al. Atrial tachycardia after circumferential pulmonary vein ablation of atrial fibrillation. Mechanistic insights, results of catheter ablation, and risk factors for recurrence. J Am Coll Cardiol 2007; 50: 1781-7.

200. Deisenhofer I, Estner H, Zrenner B, et al. Left atrial tachycardia after circumferential pulmonary vein ablation for atrial fibrillation: incidence, electrophysiological characteristics, and results of radiofrequency ablation. Europace 2006; 8: 573-82.

201. Choi J-I, Pak H-N, Park JS, et al. Clinical significance of early recurrences of atrial tachycardia after atrial fibrillation ablation. J Cardiovasc Electrophysiol, 2010; 21: 1331-7.

202. Knecht S, Hocini M, Wright M, et al. Left atrial linear lesions are required for successful treatment of persistent atrial fibrillation. Eur Heart J 2008; 29: 2359-66. 


\section{FIGURE LEGENDS}

\section{Figure 1. Catheter ablation of paroxysmal lone AF: PV isolation.}

A 47-year-old male underwent catheter ablation due to a 10-year history of daily attacks of symptomatic paroxysmal lone AF, refractory to drug therapy with beta-blockers, sotalol, propafenone, and, finally flecainide. Echocardiography showed normal LA dimension $(38 \mathrm{~mm})$ and left ventricular ejection fraction $(65 \%)$. Using the electroanatomical mapping system (Ensite NavX, St Jude Medical) with CT-image integration, geometrical LA 3D-map was reconstructed and irrigation radiofrequency ablation (red dots) was performed with en-block isolation of ipsilateral PVs.

Panel A: postero-lateral LA view with circumferential antral ablation encircling left sided PVs, circumferential diagnostic (Lasso) catheter is positioned within the left superior PV.

Panel B: voltage map of LA and PVs in sinus rhythm after PV isolation. Grey and violet colors represent electrically silent regions within the PVs and electrically healthy myocardium in the remaining part of LA, respectively.

Panel C: electrical isolation of PV in sinus rhythm, with abrupt loss of PV potential recorded by circumferential diagnostic catheter (yellow signals, labeled with white arrow).

Panel D: after PV isolation, the occurrence of spontaneous repetitive short bursts of atrial tachycardia within the "arrhythmogenic" PV is recorded by the Lasso catheter (yellow signals, labeled with white arrow). However, stable sinus rhythm is maintained, due to exit PV-LA block after ablation.

During the one-year follow-up after the procedure, the patient was free of AF without drug therapy.

$\mathrm{AF}=$ atrial fibrillation; $\mathrm{LA}=\mathrm{left}$ atrium; $\mathrm{CT}=$ computed tomography; $\mathrm{PV}=$ pulmonary vein.

\section{Figure 2. Catheter ablation of paroxysmal AF: elimination of non-PV triggers.}

A 37-year old female patient has been referred for the second catheter ablation procedure due to highly symptomatic and frequent episodes of paroxysmal AF. In the index procedure fluoroscopically guided segmental ostial isolation of all PVs was successfully accomplished, however the patient experienced recurrence of AF in the following weeks. At the beginning of the redo procedure, all PVs were revisited and their stable electrical isolation was confirmed. Using the catecholamine challenge and pacing maneuvers, an ectopic focus in SVC was identified. Using irrigation radiofrequency catheter, electrical isolation of SCV was successfully achieved in association with AF noninducibility at the end of procedure. Over the follow up of 6 months the patient was free of symptomatic AF without antiarrhythmic drugs.

Panels A and B: fluoroscopic position of circumferential diagnostic catheter within the SCV and ablation catheter at the posterolateral aspect of SCV-atrial junction. Before RF application, high output pacing was performed to evaluate the proximity to right phrenic nerve.

Panel C: ablation at this site resulted in electrical isolation of SCV during sinus tachycardia, with elimination of SVC potentials at the Lasso catheter (white arrow).

$\mathrm{AF}=$ atrial fibrillation; $\mathrm{PV}=$ pulmonary vein; $\mathrm{SCV}=$ superior caval vein. 


\section{Figure 3. Catheter ablation of persistent AF: PV isolation and substrate modification.}

A 57-year-old male presented with previously undiagnosed persistent AF with uncontrolled rate and symptoms and signs of congestive heart failure. Echocardiography revealed left ventricular systolic dysfunction with EF of $35 \%$ and moderate LA dilatation $(44 \mathrm{~mm})$, while coronary angiogram was normal. Treatment with amiodarone and a beta blocker as well as therapy for heart failure were instituted. Several months later he was subjected to catheter ablation of AF, due to the clinical suspicion of tachyarrhythmia-related cardiomyopathy.

Panel A: fusion of 3D anatomical LA map with CT image (Ensite NavX, St Jude Medical), posterior LA view (left side of image) and right lateral view (right side of image). Irrigation RF ablation (red dots) included circumferential antral PV isolation coupled with LA substrate modification by means of linear ablation. Linear set consisted of roof line + inferior line ("posterior box" lesion) and endocardial linear disconnection of coronary sinus.

Panel B: isolation of PVs during ongoing AF. Spontaneous slow automaticity within the PV was recorded (white arrow), while AF continued in the remaining part of the LA.

Panel C: during the LA linear ablation, AF has "organized" to an atrial tachycardia with fast ventricular response and further LA substrate ablation resulted in tachycardia termination with restoration of sinus rhythm. At the end of the procedure revision of all PVs and lines was performed to confirm the conduction block.

Three months following the procedure, echocardiography demonstrated complete recovery of the left ventricular systolic function (EF 60\%) and all drugs, except beta blocker, were discontinued. Over the next 12 months, the patient was free of AF.

$\mathrm{AF}=$ atrial fibrillation; $\mathrm{LA}=\mathrm{left}$ atrium; $\mathrm{RF}=$ radiofrequency; $\mathrm{PV}=$ pulmonary vein; $\mathrm{EF}=$ ejection fraction; $\mathrm{CT}=$ computed tomography. 